\title{
ÁREAS LÉXICAS EN UNA ENCRUCIJADA LINGÜÍSTICA
}

I. Un estudio que tenga como objeto el léxico dialectal es hoy doblemente conflictivo. Fin efecto, por una parte, la mayoría de los lingüistas no han visto con claridad el lugar que puede corresponder a los estudios dialectales dentro de una linguiistica informada por los puntos de vista y los métodos de las más modernas escuelas, $\mathrm{y}$, por otra parte, no hará falta insistir en el hecho de que el aspecto léxico de una lengua es el que más se ha resistido a ser encuadrado en unas estructuras simples o ser regulado de una manera sistemática. No vamos a discutir la problemática que plantean estas premisas, en primer lugar, porque nuestro objetivo ahora no es este, y, en scgundo lugar, porque tenemos el propúsito deliberado de no caer en una discusión que en ocasiones ha llegado a ser bizantina. Listamos convencidos de que el valor de una investigación lingüística no depende de si tiene como objeto un dialecto o una lengua común, sino más bien de los criterios que la informan y clel grado de rigor cientifico con que se lleva a cabo. No hay que olvidar, sin embargo, algo importante: la investigación lingüística realizada sobre una lengua común parte de unos materiales que, además de los textos literarios y los repertorios (gramáticas $y$ diccionarios), proporciona el conocimiento que el propio lingüista tiene de la lengua; es decir, parte de unos datos que el investigador encuentra "a mano». I.a investigación sobre el habla dialectal, en cambio, tiene como tarea previa la recolección de unos materiales que el lingiiista de antemano ignora y que no encuentra normalmente en textos ni en repertorios, que, si existen, puede que no sean adecuados a la finalidad de su estudio. El descrédito en que se encuentran actualmente los estudios dialectales ha venido condicionado en gran manera por la falta de rigor con que durante una larga época de la historia de la lingüística han sido realizados, por los criterios no sienpre lo suficientemente científicos que los han infor- 
mado, y por el hecho de que un buen número de las publicaciones que se encuentran entre ellos tiene como única finalidad la exaltación de unas, a veces supuestas, singularidades dialectales de un habla local, finalidad que puede ser muy laudable desde ciertos puntos de vista, pero que poco tiene que ver con la ciencia lingüística.

2. A la hora de establecer fronteras lingüísticas (entre lenguas 0 . cntre dialectos de una misma lengua) suele atenderse a criterios fonéticofonológicos y morfológicos, pues éstos son los aspectos más estables en toda lengua, debido, indudablemente, a la mayor trabazón del sistema que forman sus respectivos elementos. De rechazo, el aspecto léxico suele quedar desatendido, o bien la atención que a él se dedica suele quedar centrada en la elaboración de vocabularios mejor o peor construidos, en los que se recogen aquellos términos más o menos característicos de una localidad o de una región, sobre todo aquellos que pueden conferirle una persomalidad propia frente a la lengua comín o frente a otros dialectos de mayor extensión geográfica o de mayor consideración social. Por una parte, este tipo de estudios no son todo lo abundantes que sería de desear, y', por otra parte, suelen estar elaborados con criterios no coincidentes; la primera circunstancia hace que en los estudios de conjunto siempre se mencionen los mismos puntos de reterencia, dando con ello a menudo una idea equivocada de la importancia que tienen dentro de su ámbito lingǘstico; la segunda circunstancia hace realmente difícil, y en ocasiones. prácticamente imposible, obtener una visión global basada en los estudios parciales de que se dispone. Si algo hay que lamentar pues, desde este punto de vista, es que el lingüista actual no disponga de unos repertorios dialectales más abundantes, completos y rigurosos, a causa de lo cual no puede tener siempre una idea exacta, coherente y operante de la variada realidad de una lengua determinada.

3. Iil léxico de una lengua, aparte de su carácter menos orgánico, al que ya hemos aludido, es el aspecto más movedizo e inestable de ésta, en el sentido de que sus clementos se propagan o caen en desuso con mayor facilidad y rapidez que los elementos fonológicos o gramaticales. Lo que nos interesa poncr de relieve aquí no es este hecho, conocido de todos. sino su repercusión en la lengua considerada desde el punto de vista de su variedad geográfica; en efecto, el cuarteamiento de que es objeto el dominio geográfico de una lengua es mucho mayor en el aspecto léxico que en cualquiera de los otros dos aspectos menciomados, precisamente porque, además de las diferencias de base originaria que existen en diversas áreas dialectales de una misma lengua, el ritmo de cambio y de alteración del léxico no es igual en todas ellas, lo cual da lugar a una gran jrofusión de soluciones distintas. Por ello nos 
parece de sumo interés el establecimiento de las áreas léxicas dentro de cada lengua, con el mayor rigor y exactitud posibles. Los atlas lingiiísticos son un elemento de inapreciable valor para este cometido siempre que la red de localidades sea lo suficientemente espesa como para no dejar amplias zonas sin información.

4. Por lo que respecta al catalán, del que vamos a ocuparnos, disponemos del $A L C^{1}$ y del $D C V B^{2}$, como principales repertorios de materiales ${ }^{3}$. Fil primero tiene una serie de deficiencias de método $y$ de información, a las cuales une, por lo cque ahora nos afecta, el reducido múmero de localidades 4; el segundo, obra más rigurosa, tampoco es suficiente en determinados casos, aunqie tiene el mérito de haber recogido toda la información existente en estudios dispersos hasta la lecha de su publicación, además de los datos obtenidos expresamente para él. Fisperamos que la publicación del $A L D C^{5}$ aporte nuevos datos gracias a una red de localidades más tupida (está previsto que doble las cien del $A L C)$ que permitirá establecer las áreas léxicas con mayor precisión. De

1 A. Gruirs, Atlas Lingüistic de Calalunya, publicado en dos etapas: vols. I-IV entre 1923 y 1936 , y vols. VI-VIII entre 1962 y 1964.

- A. M. Ar,Cover \& F. DE B. MoLL, Diccionari Català-Valencià-Balear, Palma de Mallorca, ro vols., publicados entre 1930 y 1962.

8 En cuanto al aragonés, que limita y se interfiere con el catalán en la zo na que estudiamos, disponemos de un solo repertorio de conjunto, de valor desigual; se trata de la obra de JERónImo Borıo, Diccionario de voces aragonesas, precedido de una introducción filológico-hislórica, con prólogo y notas de FAUSTINO SANCHO. x Gir. Segunda edición aumentada con las colccciones de voces usadas en la comarca de la Litera, autor BENITO COLL Y ALTABÁS, y de las de uso en Aragón por LUIS V. Í́PEz-PUYOLIS Y JOSE VALENZUELA DE LA ROSA. Zaragoza, I908. Eista obra. fue refundida y ampliada por J. PARDO Asso en el Nuevo Diccionario etimológico aragonés (voces, frases y modismos usados en el habla de Aragón), conteniendo todas las voces incluidas en la íltima edición de Borao..., Zaragoza, 1938. Esperamos con interés la publicación del Allas Lingïístico y Etnográfico de Aragón, de MI. ALVAR, que vendrá a solucionar gran parte de los problemas de documentación con que se encuentra el investigador actual (Véase $A L F A r$, Cuestionario, Sevilla, I963 y Proyecto de un Allas Lingïístico y Etnográfico de Aragón, $A F A$, Anejo 8, Zaragoza, 1963).

- Son ror las localidades estudiadas en el $A L C$, abarcando todo el dominio de la lengua catalaua. La escasez de este número de puntos ha sido puesta de manifiesto en diversas ocasiones; véase, por ejemplo. MI. ALVAR, Catalan y aragonés en las regiones fronterizas, $A M C I L R$, VII, p. 738: "No se ine oculta la necesidad de adensar la red de puntos, pero los datos del $A L C$ servirán, al inenos, para aplicar unos principios estadisticos....

- Atlas Lingǘstic del Domini Catala, obra cn curso de realización, dirigida por A. M. BADí MIARGARit y J. VENY CIAR (el cuestionario fue editado en I965). 
todas formas, nuestra dedicación durante varios años al trabajo de campo para el $A L D C$ nos ha hecho comprobar que en las zonas fronterizas suele existir una proniscuidad tal en el aspecto léxico, que no se puede tener una idea exacta de su repartición en ellas si no se llevan a cabo investigaciones en prácticamente todas las localidades. Tal convencimiento nos llevó a realizar la experiencia en una zona que después se nos ha manifestado como privilegiada en este aspecto, a juzgar por los resultados de nuestra investigación. El trabajo de campo que hemos llevado a cabo nos ha proporcionado una cantidad de datos considerable, algunos de ellos inéditos; estos materiales configuran una serie de fenómenos de repartición, de los cuales vamos a dar noticia en este breve avance de lo que será la obra que preparamos con ellos.

5. I a zona que ha sido objeto de nuestro estudio comprende un núcleo fundamental de veinticinco municipios lingüisticamente catalanes pertenecientes a la provincia de Teruel, además de tres municipios correspondientes a la provincia de Tarragona, cinco a la de Castellón, y otros seis de Teruel, pero de habla castellano-aragonesa, que nos sirven de punto de referencia; en total, pues, han sido realizadas encuestas en trcinta y nueve puntos ${ }^{1}$. Esta zona se halla en plena frontera lingüistica catalano-aragonesa. en la región conocida comínmente con el nombre de Bajo Aragón. En ella no habian sido llevadas a cabo investigaciones linguísticas sistemáticas, por lo cual se ha tenido durante muchos años

- Fn cl mapa núm. I puede observarse la situación de las localidades. Para el establecimiento de los nombres de éstas hemos tenido en cuenta preferentemente la promunciación popular, por lo cual no siempre coinciden, por una parte con la denominación oficial, $y$, por otra, con la establecida por J. CoRominas (Els noms als municipis de la Calalunya aragonesa, RLR, I95.9, XXIII, pp. 35-63 y 30433S, reproducido en Estudis de toponimia catalana. II, Barcelona, 1970, pp. 43I 41): hemos adoptado la ortografia catalana en los nombres de los municipios que lingüisticamente lo son. I,os nombres que tienen alguna discrepancia, aunque sea gráfica, en los sentidos indicados, son los siguientes (entre paréntesis ponemos la denominación oficial; la propuesta por Corominas, en su caso, va también entre paréntesis, pero en cursiva): Aigruaviva (Aguaviva, Aigzaviva de Bergantes). La Torre V'elilla (Torrevelilla, La Torre de Vilella), La Codonyera (La Codoñera), Valljunquera (Valjunquera), Bellmunt (Belmonte de Mezquin, Bellmunt de Mesqui). La Canyada (La Cañada de Verich, La Canyada de Beric), I,a Sorollera (La Cerollera), Ràfels (Ráfales), I'órnols (Fórnoles), La Torre del Conte (Torre del Compte), Ia Vall del Tormo (Valdeltormo), Massalió (Mazaleón). Calaceit (Calaceite), Caseres (Caseras), Arenys de Iledó (Aréns de Lled6), Horta de Sant Joan (Horta de San Juan), Arnes (Arnés), Cretes (Cretas), Vall-de-roures (Valderohres), licseit (Beceite), Fondespala (Fuentespalda, Fondespalla), Montroigy (Mlouroyo, Mont-roig de Thstailins), Torredarques (Torre de Arcns), Herbers (IIcrbís), Sorita ('Zorita del Maestrazgo), Torrecilla ('Torrecilla de Alcañiz). 
una idea equivocada, no sólo de las características de sus hablas, sino incluso del trazado de la frontera lingüistica en el sector que le corresponde ${ }^{1}$; las referencias, en obras publicadas, a alguno de los puntos de la zona que nos ocupa son muy pocas ${ }^{2}$. Fista escasez contrasta con el gran interés que, desde épocas tempranas de la historia de la dialectología, despertó en los estudiosos la zona del Alto Aragón, en la que se observa también una promiscuidad lingïística concretada en la no coincidencia de isoglosas correspondientes a diversos fenómenos; en el mismo $A L C$ figuran diversas localidades fronterizas correspondientes a la

1 Del problema de la frontera lingüistica en esta zona y de su historiografía nos hemos ocupado detenidamente en nuestra tesis doctoral: La lengua catalana fronteriza en cl Bajo Aragón meridional. Estrsdio fonológico, todavia inédita, leída en octubre de 1973 .

2 Se hace alguna referencia al habla de Aiguaviva en el trabajo de J. HADWriar, Sprachgrenzen und Grenzmtındarten des Valcncianischen, $7 R P h, 1905$. XXIX, pp. 7I2-73r; existe un reducido Vocabulari de Penarroja, de M. PAIIARI:S ( $B D C$, I921, IX, pp. G9-72), con unas ciento cuarenta voces; también encontramos una referencia al habla de Bellumunt en Les e tonniques del valencià. de G. Renat I lisroís (Miscel-lània Fabra, Buenos Aires, 1943, 1p. 349-362); J. Coromins, en su estuclio sobre toponinia ya citado (Cf. nota I, p. 234) hace referencia al habla de ciertas localidades (véase s. v. Aiguaviva, La Ginebrosa y La Torre de Vilella). Hay que tener en cuenta también el detallado estudio fonético que M. SAncins GunRnion dedicó al habla de Aiguaviva (Noticia del habla de Agmaviva de Araginn, RJ JE, 19.49, XXXIII, pp. 15-(65), algunos de cuyos datos reenge en su trabajo posterior l'actores histúricos de los dialectos catalanes (Listudios dedicados a Menéndez Pidal, VI. Madrid, 1956, p1). I $^{\mathrm{r}} \mathrm{-186)}$. Más recientes son la obra de $\Lambda$. Quintana, l:l parlar de la Codonyera, 'Tesis doctoral, inédita, s. a. [1972]; y nuestra propia tesis cloctoral citada en la nota anterior. Sin embargo. de todos cstos trabajos, los únicos que tocan aspectos léxicos de una manera directa son cl artículo de Pallarés sobre Pena-roja y la tesis de Quintana sobre La Codonyera; aunque algunos otros, como el de Sanchis solsre Aiguariva, y el nuestro, a pesar de no tener como finalidad el estudio del léxico, aportau un caudal de inateriales aprovechables en este scutido.

Por otra parte, las localidades de Aiguaviva y Valljunquera fueron visitadas por los investigadores del $A L P I$ y figuran en el volumen publicado de esta obra; los investigadores del $D C V B$ visitaron, además de éstas, la localidad de Calaceit, la cual figura, además, como punto estudiado en el $A L C$ y en la obra de $F$. DE B. MoLr. La flexió verbal en els dialectes catalans, AORLL, 1929, II, pP. 73184; 1930, III, pp. 73-168; 1931, IV, pp. 9-104; 1932, V, pp. 9-72. El $A L D C$ incluirá las localidades de I,a Codonyera, I,a Torre Velilla, La Ginebrosa, Aiguaviva, 13cllmunt, Massalió, Vall-de-rourcs y Sorita, en las que hemos llevado a cabo las cncuestas personalmente; por otra parte, en el proyecto del ALFAr (véase nucstra nota 3. j. 23.3) figuran como previstas las localidades de $\Lambda$ iguaviva, La Codonyera, Calaceit, Vall-de-roures y Pena-roja. 
z.ona del Alto Aragón, mientras se olvida prácticamente la que nosotros. ahora estudiamos, de la cual sólo consta la localidad de Calaceit ${ }^{2}$.

0 . Durante la zealización de las ercuestas para el $A L D C$ en la zona mencionada, observamos la gran riqueza de la lengua de aquellas localidades, y, aparte de los fenómenos fonológicos que hemos cstudiado monogríficamente, nos llamó la atención la gran diversidad de su léxico, puesto que 10 sólo era notoria la interferencia mutua de catalán y castellano-aragonés, sino que aparecían soluciones correspondientes a diversos dialectos catalanes, lo cual no es de extrañar, dada la especial situación geográfica de la zona, que posibilita la concurrencia de características léxicas propias del leridano, del valeuciano, y también del catalán oriental, con especial presencia de algunos términos propios de la zona de 'lortosa o del Campo de Tarragona. I,a constatación de este hecho nos inpulsó a confeccionar sobre la marcha un breve cuestionario (427 preguntas) basándonos en la experiencia de aquellas hablas adquiririda durante la rcalización de las citaclas encuestas para el $A J . D C$. $1: 1$ interés de nuestra investigación estriba en el heclio de haber realizado la cncuesta en todas las localidades que comprende la zona descrita, con lo cual la delinitación de los fenómenos léxicos estudiados puede alcanzar un notable grado de exactitud. I as encuestas fueron realizadas durante los veranos de 197 I y I972. El método utilizado ha sido siempre el de la pregunta indirecta; las respuestas no han sido grabadas en cinta magnética, sino transcritas directamente a los cuadernos; la transcripción se ha hecho en alfabeto fonético, puesto que, aunque el interés del cuestionario es fundamentalmente léxico, no quisimos desaprorechar la posibilidad de una información más amplia. Un breve periodo de iniciación en el estudio de las principales peculiaridades de la zona nos permitió dirigirnos a los informadores de modo que no se contaminaran con nuestros propios hábitos lingüísticos. Fin cuanto a los

1 Para darnos cuenta de hasta qué punto la naturaleza de los repertorios en que debe basarse el lingüista condicionan sus investigaciones, pudiendo apartarlas, en ocasiones, de la realiclad, notemos la afirmación que hace M. AIVAR en el trabajo ya citado (véase nuestra nota $r$, p. 234): «Mis referencias tendrán - una y otra vez- a Taularite y Binéfar como limites extremos en el mediodia. Aunque siempre me he fijado en localidades aragonesas situadas al sur de estos pueblos, súlo con rareza he podido obtener materiales de interés" (p. 739). I as investigaciones sistemíticas que hemos realizado en la zona que nos ocupa demuestran clarancute la existencia de materiales dignos de consideración, de los cuales vamos a inclitir soblo una peyueña parte, a modo de cjemplos ilustralivos, en este arance de muestras investigaciones. 
sujetos, nos hemos atenido a los principios que suelen presidir la realización de toda encuesta dialectal: todos ellos son naturales de la localidad y de familia de ascendencia local; los cónyuges respectivos son tanbién, ell la mayoría de los casos, de la misma población; por otra parte, hemos tomado las suficientes precauciones para asegurar que fueran representantes genuinos del habla local y que sus hábitos lingüisticos no hubieran sido influidos por eventuales contactos o por estancias fuera de la población. Generalmente el informador ha sido un individuo perteneciente a la generación más anciana, o, eventualmente, a la que le sigue.

7. I,os resultados de esta investigación, que actualmente tenemos cartografiados en forma de borrador en los correspondientes mapas (uno por cuestión), ofrecen tal variedad de fenómenos, que prácticamente es imposible resumirlos de una manera cumplida en este artículo. I.a contemplación de estos resultados nos sugiere, en principio, dos tipos de consideraciones: cn primer lugar, las que derivan de la dirersa repartición de las distintas fornias léxicas que corresponden a cada uno de los conceptos que son objeto de estudio, y de las influencias de distintos dialectos, o prolongaciones de ellos, que estas diferentes formas suponen; en segundo lugar, las que resultan de un estudio comparativo entre mapas de significados correspondientes al mismo campo conceptual, o a campos conceptuales afines, atendiendo a las posibles variaciones dentro de pequeitas estructuras léxicas y a las relaciones semánticas entre sus elementos. Vamos a ocuparnos por ahora sólo del primero de estos dos grandes aspectos, porque creemos que es suficiente para dar una idea cabal, en forma de muestra, del trabajo que venimos realizando y de sus posibilidades. De momento no es otra nuestra intención.

8. La diferencia entre los resultados correspondientes a las distintas cuestiones va desde la obtención de una uinica forma léxica para toda 1a zona (tanto para la parte lingüísticamente catalana, como para la castellano-aragonesa) hasta una diversidad de formas léxicas casi inimaginable en una área tan reducida. Entre estos dos extremos se encuentran una gran cantidad de resultados variados, que intentaremos sistematizar en la medida de lo posible. Citaremos, en primer lugar, algunos casos de uniformidad total, $y$, a continuación, iremos tratando soluciones de complejidad creciente. Diversos conceptos, como ya hemos indicado, son representados cada uno de ellos por una forma léxica en todas las localidades estudiadas (sin variaciones dignas de mención ni aun desde el punto de vista fonćtico) tanto si pertenecen al dominio catalán, como 
si se encuentran dentro de la zona castellano-aragonesa; entre estos conceptos podemos citar, como representativos, los siguientes ${ }^{1}$ :

CONCEPTO

"dueño de una tierra o de una casa" "rayo"

"avena"

"encina"

"feo"
FORMA I,EXICA

anio
rayo
avena
carrasca
fro

anio

rajo

fro

Insistimos en el hecho de que, en los ejemplos citados, la uniformidad es total, tanto desde el punto de vista del tipo léxico utilizado, como si atenclemus a la estructura fonológica de la forma léxica, o incluso a la naturaleza fonćtica de los clementos que la componen. Encoutramos, sin embargo, numerosos casos de coincidencia de tipo léxico con algunas discrepancias de maturaleza formal que ponen de manificsto ciertas diferencias, sea cn los sistemas fonológicos de las hablas de la zona, sea en la estructura fonológica de la palabra como consecuencia de fenómenos

I Obsérvese que en estos casos sicmpre se trata de uu tipo léxico común al español y al catalíu, como en el caso de amo, o bien de una penetración del léxico castellano o castellano-aragonés, como en los denús ejemplos (véunse en la nota siguicnte unos tipos léxicos más gencralizados en catalán, pero que perviven en aragonćs). Liajo es un castellanisuio bastante exteudido (frente al catalán llamp) por la región valenciana y por toda la zona fronteriza con el castellano-aragonés (scgún el mapa 92 I del $A L C$, ocuya uniformencnte la zona alicantina, y se encucutra cu algunas otras localidades valencianas -entre ellas Morella, próxima a mestra zona - y en Gandesa, Calaceit, Maella, Mequinensa, Fraga, Lérida y la parte del Alto Aragón; el DCV $B$ lo recoge en Tamarite de Litera, Fraga, Gaudesa, Tortosa, Ibiza, y en el País Valenciano en general). La forma avena (frente a cirada) ticne, a grandes rasgos, una repartición parccida a la anterior ( $A L C$, mapa ${ }^{8} 8$ ); el $D C V B$ la da como propia de la Cataluña meridional y del Reino de Valencin, aunque cabe suponer, por los ejemplos de textos aducidos, que en la lengua antigua estaba unás generalizada. Semejante es también la repartición de la forma carrasca (frente al catalán alzina) ( $A L C$, mapa 73); este tipo léxico aparece eu diversos estudios pertenecientes sea a la zoua lingüistica catalana, sea a la aragonesa (ALVAR, Cuevas de Cañart; MrSTrE, Voc. Tortosa; CASACUberta-Coronunes, Parlars aragonesos; FerRaz, Voc. Alla Ribagorza; Corbeld loc. Ribagorza); el $D C V B$ la da como propia del Priorato, Torlosa, Ibiza y del valenciano en gencral. Iil área de la forma fco (freute al catalán lleig) no está suficientemente documentada (cl $D C V B$ lo incluye sólo como castellanismo inadmisible), pero podemos suponer que ticne una cicrta vitalidad en el l'ais Valenciano; es citada esta forma, al lado de lleig, cu Salvador, Voc. Benassal. 
evolutivos que han afectado a la lengua a lo largo de su historia. Como representantes del primero de estos fenónenos podemos citar los siguientes ejemplos, que podrían ampliarse enormemente en su número, pues son niaterializaciones de diferencias sistenáticas ${ }^{1}$ :

SIGNIPICANO

«orujo de la uva»

«hoz"

"enebro"
SIGNIIICANTIES

$$
\begin{aligned}
& \text { [brisa }]-[\text { briza }] \\
& {[\text { falo]-[fals] }} \\
& {[\text { xinébro }],[-e]-[\text { cinébre }],[\check{z}-]}
\end{aligned}
$$

Del segundo caso ramos a aducir un mayor nimero de ejemplos, pues este fenómeno no presenta el mismo tipo de sistematicidad que el anterior ${ }^{2}$ :

SIGNINICADO

"mordisco, bocado»

«hollíi»"

«hermano»
SIGNIFICANII:S

$$
\begin{aligned}
& {[\text { [ntoćso }]-[\text { [nos }]} \\
& {[\text { olin }]-[\text { folí }]} \\
& {[\text { crmáno] }-[\text { žérmá }],[\hat{c}-]}
\end{aligned}
$$

1 La forma brisa aparece con este significado en BORAO, como término aragonés; la recoge P'ARDO, y la encontramos también el AI,VAR, Salvatierra; a parece también en el Diccionario de la RAE sin indicación regional; es el tipo léxico usual para este concepto en catalín. I, a forma falz (C. catalán fals) se cucuentra documcntada en diversos trabajos, referida a la zona aragonesa (LóPEz PUyorrs, Voces Aragón; P'ardo; Baní, Biclsa; Arvar, Cucuas de Cañart; Casacubir'raConominas, Parlars aragonesos; etc.). I,a forma ginebro (o gincbre) (Cf. catalán ginebre) no se encuentra, cll cambio, tall documentada en aragonés; CoLL Y Arínins, Voces La Litera, la cita únicamente como recogida de la obra de Is. I,Oscos, Seric imprrfocta de las plantas aragonesas espontineas; I'ARUO no la conserva en su diccionario; CasacummRta-Conominds, Parlars aragonesos, la localiza en Puebla de Itijar y Caspe, aduciendo, además, las formas chinelro (en Plan, Gistáin y Hecho), chenebro (cn Ansó) y chenipro (en Biclsa, donde BADí recoge chinipro): ARNAL, Voc. alto-aragonés, cita chinebro y chinebrera.

2 In los conceptos que se ejemplifican aqui no existen discrepancias propiamente léxicas, puesto que las formas que los representan en cada caso provienen de un mismo étino y difieren únicamente en aquellos rasgos a que ha dado lugar la evolución respectiva en catalán y en castellawo, y, en su caso, eu aragonés, de una misma forma originaria. Asi se ejemplifican fenómenos como la diptongación o no diptongación de la o breve tónica latina (muteso-mos), la caida de ir inicial (hollin-folli), la conservación o pérdida de -N final (en el misıno ejemplo), o de -o final (repelos-repels), y toda una serie de fenómenos de indole evolutiva, aunque en algunos casos son reflcjo de una discrepancia latina, como pucde ser la diferencia acentual que está en la base de la parcja romper-rompre. 
"palmo"

"espejo"

"rab)adái»"

"padrastros de los dedos"

"ular la primera labor al campo"

"dar la segunda labor al campo"

"dar la tercera labor al cámpo" [pálmo] - [pam]

[espéxo] - [espil $]$

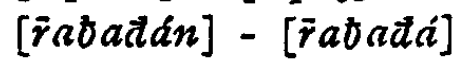

[ricpélos] - [ricpéls]

[rompór] - [rómpre]

[manlornár] - [mantorná]

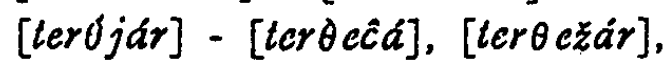

[terseĉáa], [-žáa

9. Hasta aquí hemos visto conceptos designados por un mismo tipo léxico en toda la zona que estudiamos, primero sin variaciones en la estructura de si forma de expresión, luego con ellas. Vanos a considerar ahora algunos conceptos designados ell nuestra zona por dos tipos léxicos que la dividen en dos partes, estableciendo una frontera propiaincute léxica. Ahora bien, los distintos casos estudiados en los que se da cste tipo de resultado configuran diversas fronteras. Iin primer lugar hay que decir que son bastantes lus pares de tipos léxicos (correspondientes a un mismo concepto) cuya frontera mutua coincide con la frontcra lingüistica entre catalán y castellano-aragonés establecida con criterios fonológicos y morfológicos; he aquí algunos de ellos ${ }^{1}$ :

$$
\begin{aligned}
& \text { sucio - brut } \\
& \text { subir - pujar } \\
& \text { tomar - pendre } \\
& \text { trigo - blat } \\
& \text { jeme - forc }
\end{aligned}
$$

Pero son muchos más los que configuran fronteras léxicas que no coinciden con la frontera lingüística mencionada, antes bien van dibujando nuevas líneas que rara vez coinciden entre ellas. De entre los cuatrocientos reintisiete mapas claborados, hemos separado aquellos en los que puede trazarse una frontera clara entre los dos tipos léxicos (o dos grupos distintos de ellos); han resultado seleccionados noventa y siete mapas, sin ce rtar los que tienen unos límites coincidentes con la frontera lingüística, $y$, por 10 tanto, corresponden al tipo que acabamos de ejemplificar. Pues bicn, en estos noventa y siete mapas existen setenta y cinco fronteras distiutas, es decir, en la zona que estudiamos noventa

1 In este caso, por ser totalmente accesorias, omitimos las variantes foneticas bajo las que se presentan alguwas de estas formas léxicas. Por otra parte, obsérvcse que todas ellas son formas gencralizadas en la lengua común, tanto las castellauas, como las catalanas. 
y siete conceptos configuran setenta y cinco fronteras no coincidentes en todo su trazado, sin contar, evidenteme:ite, los casos de nayor complejidad a los que aludiremos más adelante. De estos noventa y siete mapas, diez coinciden con una misma frontera; tres coincilen en otra; otros tres en otra distinta; tenemos, además, ocho fronteras en cada una de las cuales coinciden dos mapas; $y$, por último, sesenta y cinco fronteras distintas con sólo un mapa cada una. La misma complejidad de esta situación impide que podamos ejemplificarla aquí de una manera completa, puesto que nos apartaríamos del carácter esquenático que pretende tener este artículo; sin embargo, nos ha parecido conveniente clar, a título orientativo, estas cifras, que, aunque puedan matizarse cuando presentenos la elaboración definitiva de estos materiales, :son por sí mismas bastantes elocuentes.

Io. Antes de pasar a presentar resultados más complejos nos detendremos brevemente en la consideración, a mo:lo de cjemplo, cie algtinos de los tipos de repartición léxica que ofrece la problemática que acabamos de resumir. lis relativamente frecuente que, ante un tipo léxico unitario en casi la totalidad de la zona estudiada, apunte por la parte de Castellón o por la de Tarragona una forma característica de estas zonas, respectivamente, o de zonas más amplias en las que están incluidas. Quizá el cjenıplo más claro de este fenómeno, entre los que tenemos recogidos, sea el que corresponde al concepto "porrón" (mapa número 2), que presenta las fornas porrón y porró cn las zonas castellana y catalana, respectivamente, pero que adopta la forma burral al sur de la frontera administrativa entre las provincias de Castellón y 'Teruel ${ }^{1}$. Iil mismo tipo de distribución puede combinarse con el que

I La forma barral, con este significado, es común cn castelloneuse y, seguill el $A L C$ (mapa I.II 1 ), se encuentra también en algunas localidades del valenciano central, conno Gandia y Sagunto; el $D C V B$ lo localiza también en Tortosa, Calaceit, Norella y Benassal; se cncuentra tambićn ell la zona linguiisticamente castellana de Valencia, como lo indican las noticias que se dan en LI.ATAS, Villar del Arzobispo (localidades de Villar del Arzobispo, Casas Bajas, Chelva, Cluulilla, Domcño, Gestalyar y La Yesa, en la zona de la provincia de Valencia lindante con Castellón, Teruel y Cuenca); también se encuentra en territorio aragonés (Alvar, Cascuas de Cañart). Con otros significados -es el nombre de distintas vasijas-- tiene una extensión mayor; parece común en Aragón como "uredoma de vidrio forrada de junco o verga" (PARDO), significado que recoge, aproximadamente, la RAE como propio de Aragón: uredoma grande y capaz de una arroba de agua o vino, poco más o menos». İ́n catalán puede tencr también el significado de "botijo" (Cf. nuestro mapa mim. I9), puntos 16 , I9 y 21 ), que recoge el $D C V B$

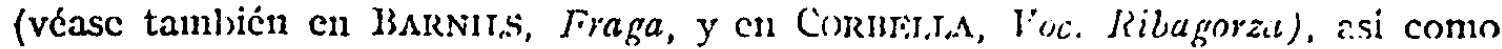
cl de otros tipos de vasija o recipiente: "rccipient per a liquids, les formes i matèria del qual varien segons les comarques..." ( $D C V B$ ).

10

(c) Consejo Superior de Investigaciones Cientificas Licencia Creative Commons 3.0 España (by-nc) 
hemos presentado en el $\S \varphi$, como sucede, por ejemplo, con los materiales correspondientes al concepto "pájaro» (mapa núm. 3), el cual nos da una zona con la forma pájaro, que se corresponde con la parte castellana, y dos áreas en la parte catalana: la nús extcusa, con diversas variantes fonćticas de moixó, y la que se corresponde aproximadamente con la zona de Castellón, que presenta la forma pardal ${ }^{1}$; esta clase de distribución enlaza con el fenómeno de repartición en tres áreas léxicas, de que trataremos más adelante ( $\$$ I3). Algunos tipos léxicos propios del valenciano tienen una área que supera por el norte la frontera administrativa con Teruel y penetran en esta provincia en forma de cuña, constituyendo una avauzada de deterninadas formas frente al tipo léxico unitario del resto de la zona estudiada, incluyendo las localidades catalanas y las castellano-aragonesas; el concepto "la tarde» (mapa núm. 4) adopta la forma la tardc en toda la zona, excepto en el área señalada en d mapa, clonde se dan diversas variantes de vesprada ${ }^{2}$; algo parecido ocurre con las formas propias del adverbio locativo de proximidad (mapa mim. 5), que prescnta la forma aquí en toda la zona, con una penetración de la modalidad act, común en valenciano ${ }^{3}$. Obsérvese, sin embargo, que las áreas dc visprada y de ací, a pesar de que representan un mismo fenómeno, no son totalmente coincidentes.

II. Hennos dicho al principio del párrafo anterior que la diferenciación léxica, en los mapas que presentan una área marginal minoritaria, puede darse por la parte del valenciano, como en los casos que acabamos de ver, y que también puede producirse como prolongación

1 Nos falta documentación precisa acerca de la repartición de las tormas léxicas pardal y moixó en catalán con el significado genérico de "pájaron (la forma propia de la lengua común y litcraria es occll). Iil $D C V B$ nos da la primera como propia del valenciano y del ibicenco, y la scgunda como generalizada en el catalán oriental y leridano. Iste concepto prescnta ciertas complicaciones de orden semántico, puesto que la misma forma pardal significa "gorrión donde no se utiliza para el concepto genérico; pero esta problemática escapa ahora a nuestra intención, únicamente añadiremos, en relación con el mismo concepto, que no hemos encontrado en territorio lingüístico aragonés ninguna de las denominaciones catalanas; pero en la localidad de Calanda hemos podido recoger la voz mosonar como verbo con el que se denomina una determinada manera de cazar pájaros.

- Vesprada, con el significado de utarden, es propio y exclusivo del valenciano, aumque la misma forma se utiliza en otros lugares con el significado de aatardecer (cu el Ampurdán y Mallorca, scgún el DCVB). En Paldarís, Voc Penarroja, aparece esta forma con el significado de tarden; obsérvese, sin embargo, que nosotios no la hemos localizado en este punto, doude hemos encontrado precisamente tarcic.

- Véase la repartición de estas dos formas ell el $A L C$ (mapa 132). 
de un tipo léxico propio de la zona nordeste (provincia de l'arragona); el concepto "colnicna" (mapa núm. 6) nos da un buen ejemplo de este fenómeno, aunque combinado con tuna mayor promiscuidad; pero olssérvese que, dentro de esta mayor variedad, se cuctientra la forma araa, que se presenta como una prolongación de la zona tarraconense y ticne una frontera clara, aunque en alguna localidad alterne con otros tipers léxicos que se dan también en el resto del área estudiada ${ }^{1}$. Algo parecido sucede con el concepto "cebada", que presenta las formas cebaia o civada en toda la zona, excepto en las localidades $I^{6}$ y $\mathrm{I}_{7}$, en el ángulo nordeste, donde se encuentra la forma ordi, que es el tipo léxico generalizado en catalán ${ }^{2}$. Concretándonos todaría a las soluciones con dos tipos léxicos, aduciremos dos ejemplos en los que se enfrentan un tipo

2 Según el $A L C$ (mapa 155), arma es la denominación propia pata el levilino y gran parte del catalín oriental, micntras que vaso es la forma gencralizarla en castelloncuse, y se cnenentra tambien en Sagnuto (Valencia) y en Undeconar (\%onat de fortosia); ch lats provinciats de Alicante y Valcucia figura generalizata la format colnicur, y suro no aparece. Iil $D C V B$ dia vetso como propio tambión de 'Tortosa. l'or otra parte, arna aparece en los repertorios aragoneses (BorAl) y PARDO) y también en $I A E$, sin indicacion de regionalismo; también en BORAO y en PARmo se encuentran los derivados ama! y amero, como sinónimos, aunque Cor, y Arimins, Voces La Litera, les da el significado de "colmenar"; con este último significado apurece también la voz arnal en Arival, Voc. allo-urayoués. Il vocablo unso, aparte de su localización castellonense, cstá documcntado con el significado que nos ccinpa en algunas polblacioncs ararionesas, cono se ulsirva en Alvar, Cilevas di Cañart y en Alvar, Siilintierra. De las formas suro o zu:o no hemos encontrado noticia en los repertorios consultados hasta ahora. Fistos distintos tipos léxicos se prestan a una scrie de consideraciones acerca de su origen, su motivación, sus relaciones mutuas, ete; pero no vamos a referirnos a estos aspectos, pues el motivo de halier aducido el mapa corresponidiente a este concepto es sólo ejemplificar la cielimitación de un tipo líxico en la \%ona liori]este de la región estudiada. Sin embargo. precisarenos que la diferencia de numbre pucle comportar una difcrencia en la materia y forma del objcto; asi. por ejemplo, en la localidad if se ntiliza amu si la colmena estí construicla con cañas y estiércol de vaca, mientras que se emplea zaso o vas si es de corcho; cn otros lugares no se hace esta distinción. Fxiste, además la denominación cuixa (o caja), que se utiliza para designar las mudernas colmenas de madera, de forma cúbica, con panales artificiales; pero, puesto que no modifica el fenómeno que presentamos, no la liemos incluido en el mapa para no complicar el aspecto grifico de éste.

2 Véase el $A L C$ (mapa r.035), donde aparece ordi como forma generalizada en todo el dominio (ordio en el Alto Aragón y La Litera), hallándose el tipo léxico cebacla, con sus diversas formas fonéticas, en Morella, Calaceit, Maella y Alicante. Fin $\Lambda \mathrm{I}, \mathrm{V} \wedge \mathrm{R}$, Salvalierra aparece ordio con el significado de kavenay, mientras que en CAsacudiota-Coronints, Parlars aragonesos, y en Batía, Voc. aragonés, aparece con el siguificado de ucebaday, que nos ocupa. 
léxico general en castellano con otro propio del catalán, siendo notable, sin embargo, la zona lingüísticamente catalana en la que el tipo léxico coincide con el castellano, con alguna diferencia fonética; obsérvense los mapas correspondicntes al concepto "cena» (núm. 7) ${ }^{1}$, y al concepto "yema de liuevo" (num. 8) 2; nótese de paso que las fronteras de uno y otro no sun tampoco exactamente coincidentes entre sí.

I2. Otro tipo de disposición que adoptan los materiales correspondientes a varios de los conceptos estudiados es la de una área aislada o, cuando menos, intermedia, con un tipo léxico distinto del resto de la zona, sin menoscabo de que ésta pueda presentar, por lo demás, un aspecto uniforme, o bien estar dividida a su vez en dos sectores. Fista área intermedia puede ser muy reducida o tener mayores dimensiones, liasta llegar a presentarse, en realidad, como una escisión de la zona en tres áreas léxicas distintas sin que se pueda hablar en realidad de aislamiento de ninguna de ellas; pero de los casos que se ajustan a este i1timo tipo nos ocuparemos en el próximo párrafo. Fin todos los ejemplos que hemos encontrado de áreas aisladas se da la circunstancia de que éstas se cncucutran en la zona más estrictamente fronteriza, de tal modo que, como afirmación general susceptible de ser muy matizada, podríamos decir que en muchos casos las soluciones más gencralizadas en el castellano-aragonés y en el catalán de esta zona, respectivaniente, no entran en contacto geográfico de una manera directa, sino que entre ellas se interpone una forma distinta, normalmente peculiar, cuyos rasgos diferenciadores pueden ser de índole varia. Los ejemplos que hemos seleccionado, y que vamos a aducir seguidamente, presentan áreas de diversa extensión $\mathrm{y}$, además, distintos rasgos diferenciales. E1 concepto "calle" (mapa núm. 9) presenta la forma calle en la zona castellanoaragonesa y la forma carrer en la catalana, coincidiendo esta diferencia exactamente con la frontera lingiística; ahora bien, en las localidades I y 4 la designación de este concepto adopta la forma carrera, que

1 El wapa I.196 del $A L C$ se ocupa del concepto «cenar", como verbo; aparece el tipo léxico sopar eu toro el dominio, excepto en Maella, Binéfar. Fonz, Graus y Campo, donde aparece el tipo cenar. Nótese que Maella está situada inmediatainente al norte de nuestro mapa, encima del punto $I_{4}$.

- La forma gema, con sus distintas posibilidades fonéticas, aparte de nuestra zona, se encuentra en Tamarite de Litera (DCVB). Fraga (BARNILs, Fraga) y la Ribagorza (CORuElLA, Voc. Ribagorza). Como forma se encuentra también en Tortosa (Alrisirle, Voc. Torlosa), pero con el significado de syema de un vegetal. 
comporta una diferencia de género respecto de la anterior ${ }^{1}$. Una zona algo más extensa abarca la forma llodo, correspondiente al concepto «barro" (mapa nim. I(i), que se encuentra entre el área de barro, correspondiente al castellano-aragonés, y la de fang, correspondiente al catalát, y que abarea las localidades $I, 2,3$ y 4 , tolas ellas estrictamente fronterizas". Mayor es todavía la extensión del área determinada por la forma vila, correspondiente al concepto "pueblo" (mapa mún. I I), que se encuentra rodeada por los descendientes del latín p o p u $1 \mathrm{um}$ (fneblo en la zona castellana y poble en la catalana); notemos, sin embargo, que dentro del área de vila encontramos dos localiclades que utilizan exclusivamente la forma lloc para referirse al mismo concepto ${ }^{3}$, y que, ade-

I I, a forma femeniusa carrera, con el significado de "calle", cs un arcaísuo catalán que se conserva en pocos lugares; el $A L C$ (mapa +28$)$ lo docuninnta sólo en la localidad de Beriasque, a la cual se atribuye también en Corner.LA, l'oc. libagorza; también se halla documentada en otras localidades altoaragonesas (Gistíin, IBielsa y Ansó, según Cnsicubierta-Coronuntis, I'arlars aragonesos): a IBcnasque y a Biclsa se atribuye asimismo en BADf Birlsa. Fucra de la zona del Alto Aragón no hemos encontrado documentarla esta forma con cl mismo significado, por 10 que las nuevas referencias que aportanos ticncn un particular valur. Notemos que csta forma se utiliza también cu Mallorca, pero con un significado más restringido: el de "espacio de calle que se encuentra aute la fachada de una casa" (véase el $D C Y B$, s. v., y VErv, Paralelismos, I, página 53). El español conoce también un significado afin de esta forma: "calle que fue antes camino" ( $R A E$, s. v. carrera, $5 .^{2}$ acepción).

2 La forma llodo sólo liemos podido documentarla en el $D C V B$, que la cita como castellanismo y sin referencia alguna, ni literaria ni clialectal; pero ni aun en estc caso se le atribuye el significado de "barrc", sino que se la hace sinónima de llot, que significa "limo, cieno". No hay duda de que en los puntos scĩalados en nuestro mapa la forma llodo significa "barro" y no "cieno", puesto que este segundo significado vicne representado por las formas charquin en el punto $I$, tarquin en el punto 2, tarquiz en el punto 3, y tarqul en el punto 4; no aducimos el mapa corrcspondiente a este concepto que también forma parte de nuestros matcriales, porque prescnta una distribución geográfica muy diferente de la de los casos que estanos consirierando, $y$, aparte de los puntos que hemos mencionado ex profeso, no aporta elenentos de juicio muevos accrea de la distribución de los tipos léxicos que nos ocupan ahora.

3 Es de notar que todas las formas que aparecen en nuestros materiales (piseblo y lugar para el castellano; toble, vila y lloc para el catalán) son voces que pertencecn a la lengua connun, pero que no son sinónimos, como aqui, sino que se presentan como términos de una gradación, que, de nuayor a menor importanria. sería: ciudad, villa, pueblo, lugar, aldea, para el español, y, para el catalín, ciutnt, vila, poble, llogaret, (lloc no aparece en FARRA y si en el DCVB: "3. Nucli de població petit, nenor que la vila»!. Insistinos en el hecho de que en los resultados que aparecen en muestro mậa está ajena cualquier intención valorativa como las mencionadas, asi como cualg̣ier referencia a la mayor o newor extensión o número 
mís, estas localidades son las mismas (Aiguaviva y I,a Codonyera) que, en el caso del concepto "calle" (mapa núm. 9), que acabamos de considerar, presentaban la forma peculiar carrera; notenios también que en los puntos 34 y 36 , contiguos a I y 4 , respectivamente, existe, junto a 1it forma pucblo, la forma ligar, que es la castellana correspondiente a la catalana $l l o c$, que se da en éstas, con lo cual se produce una confluencia de circunstancias que creemos puede contribuir al conociniento de los fenómenos de repartición léxica.

13. Dentro del tipo de distribución con áreas léxicas intermedias, aduciremos tres ejemplos distintos de casos en que estas áreas son ya nús extensas que las que hemos considerado en el párrafo anterior $y$, además, no se trata ya de áreas propiamente aisladas, como aquéllas, porque no quedan cerradas dentro de la zona que estudiamos. Fin el mapa nímero $[2$, correspondiente al concepto "fajina, montón de haces de mies", encontramos los tipos léxicos fajina y garbcra, que corresponden, respectivamente, a las zonas castellano-aragonesa y catalana; pero cutre cstos dos tipos se chectentra una zona con la forma sellar ${ }^{\mathbf{1}}$; notemos tambićn en este mapa la singularidad de la localidad i5 con la forma [klapé], que no hemos hallado documentada con este significado

de habitantes: estas denominaciones son las que espontáneamente dan los habitantes de cada población a su propio núcleo urbano o a los que les rodean, y sólo distinguen entre la denominación consignada en cada punto y la de capital (normalmente desconocen cindud); cn el caso de que quieran matizar, lo hacen a base de calificativos, como piqueño, grandc, importante (petit, gran, important).

1 Fin el $A L C$ (mapa 876 ) aparcce garbera como general a todo el douninio; sólo aparecen variautes del tipo léxico fajina en Graus, Campo, Benasque y Durro, torlas cllas en el Alto Aragón; en algumas localidades fronterizas se encuentran formas como carga y monjoin, que no aparecen en mestros materiales. La forna garbera no sólo es propia del cutalín: la RAI: la recoge cono propia de Aragón, Andalucia y Murcia. Por otra parte, el tipo léxico faiina tiene su correspondiente catalín fcixina, que se halla en divcrsas localidades ribagorzanas (véase el $D C V B$ ). Iin cambio, la forma scllar sólo la encontramos en Tresor, con tres acepciones más o menos emparentaclas: "I. Munt de garbes que està a l'era (Alcalá de Xivert). 2. Tres renes de garbes dretes aunb dos ren:s que les colveixen (Torre de Capdella). 3. Miunt gros de llenya (Castellbo)."; el $D C V B$ nos proporciona las formas sellds, como propia únicamente de Bassella (Ait Urgell), y sellat, documentada en Solsona e Igualada, y, como ililiada de una fajinan, en Sencelles y Montuïri (Mallorca). La forma claper aparece en el $D C V B$, exclusivamente referida a Menorca, con el significado genérico de "nuontón"; también se encuentra en MESTRE, Voc. Tortosa, como montón de piedra seca cn medio de uma malezan, significado que recoge Tresor, aclemís de "turó format de rocs», atribuido a Olot. 
especíïico. I,os materiales correspondientes al concepto "cubil, cama" ${ }^{1}$ (mapa núm. I3) se agrupan tamilién en tres zonas: la primera, con el tipo léxico caina, corresponde a la parte castellano-aragonesa; dentro del área lingüística catalana se perfila una zona con diversas : ariantes formales de cubil, que queda corrio franja central, y otra en la que aparecen las formas jaf y jaf̧ana ${ }^{2}$. Unos límites menos precisos tiene el área geográfica de la forma [dotó], correspondiente al concepto "médico" (mapa número $\mathrm{I}_{4}$ ), que se encuentra entre la forma mídico (con su variante paroxítona medico), propia de la zona castellano-aragonesa, y la forma wi:etge, con sus diversas variantes fonéticas, propia de la zona catalana ${ }^{3}$. No todos los conceptos cuyas denominaciones presentan tres variantes distintas en la zona que nos ocupa se agrupan cle acuerdo con el tipo de distribución que acabamos de considerar: el concepto "serrín" (niapa número 15) presenta tres formas que, aunque coinciden en el tipo lé:ico del radical, difieren en los sufijos que intervienen en su constitución; así encontramos las formas serrin, serradura (o serradures) y serritja, con sus variantes fonéticas ${ }^{4}$; las zonas correspondientes a estos tres tipos

1 Hemus preguntado, concretamente, el nombre del liggar donde se olservan trazas, indicios o rastro (hicrba aplastada, excrementos) de haberse echarlo, para descansar en cl, nua lichre o un jabali. Iin algunos lugares la respuesta ha sido distintal si se trata de una o de otro.

2. Ios términos cubil y canna son usuales cn español, annque el primero puede significar tanto la "yacija", como la "cusva o madriguera", micntras que el segundo sólo puede referirse al lugar donde yace el animal. Por otra parte, ją es el término nsual en catalíu para designar el concepto pregruntado; no hemos encontrado documentación de la forma derivada jaçana. Is interesante notar que las distintas variantes de cubil que aparecen en muestros materiales se encueutran en la zoua lingiiisticamente catalana: el limite de estas formas frente a caria coincide estrictamente con la frontera lingüistica; en cambio, no hallamos documentación de tales formas en catalán; sólo podemos aducir, en relación con ellas, el vocablo acubillar, que aparece en J. ArADERn, Diccionari poptlar de la llengua catalana, Barcelona, I904-1906, y que recoge el $D C V B$ con esta referencia (su significado es "colccjar, arraulir; amparar; arrupir, ficar-se en un lloc just i resguardat»); y al vocablo cubillada, que aparece en Tresor, como propio del Bergadin, con cl significado de "nierada d'ocells, aninals o cuques».

3 In $A L C$ (napa g85) presenta gencralizado el tipo léxico metge, en sus diversas variantes fonćticas; la forma [dotó] aparece en liversas localidıłles, casi todlas fronterizas (Bchasque, Graus, Benabarre, Peralta, Tamarite de Litcra, liraga, Mlix, Mequinenza, Maella, Calaceit y Benasal). También hallamos documentacla esta forma en Mrsstrus, Voc. Tortosa.

4 Scrin; es la forma generalizada en español, del mismo modo que serradures y serradura son formas generalizadas en catalin. Iil tipo scrritja está documentado en SAr,vaDOR, Yoc. Benassal. pero ésta es la única referencia que recogenen el $D C V B$ y Tresor; la repartición de nuestros materiales permite suponer que está bastante generalizado (lo tenemos recogido en Vilafranca, bastante mís al sur de nuestra zona). 
configuran tres áreas con un vértice situado en el centro de la zona que estudiamos; notemos que la forma serrin, propia del castellano, penetra al este de la frontera lingiística ${ }^{1}$; por otra parte, nótese la singulariclad del punto $3 \hat{j}$ con la variante serradizo ${ }^{2}$.

I4. Iincontramos una serie de conceptos, cuyas denominaciones, de acuerclo con los tipos léxicos que presentan,-dividen la zona estudiada en cuatro árcas. Quizá uno de los ejemplos más níticlos de este fenómenu sea el que corresponde al concepto "rebaño" (mapa núm. I万́) en el scntido de que hay pocas interferencias de tipos léxicos esporádicos, y por lo tanto, las áreas queclan bien delimitadas, salvo en la parte norcleste, donde se produce el fenómeno de cruce entre ellas al clarse, en algunos casos, dos de las denominaciones en una misma localidad ${ }^{3}$; los tipos léxicos que encontramos son: ganado (pronunciado siempre [ganáu]\}), que es propio de la zona castellano-aragonesa y no sobrepasa la frontera lingïística, bestiar y rabera ; sólo en dos de las localidades de la zona castellana ha aparecido la forma rebaño, pero no de una manera cxclusiva, sino en compania de ganan, que se da en todas ellas. También podcmos considerar que se reparte en cuatro áreas el material correspondiente al concepto "gajo de un racimo de uva» (mapa num. I7), pero

1 Iil castellanisuo serrin es bastaute comuin en ciertas zonas de la frontera. y sc encuentra también, esporádicamente, eu localidades no fronterizas correspondientes al valenciano.

2 Scrradizo es forma propia del aragonés, atestiguada por BorAo y recogida por PARDO. Tiene su correspondiente en el catalán serradis, que el $D C V B$. da como propio del Aupurdán, Garrotxa, Collsacabra, Conca de Tremp, Urgel y Balaguer, es decir, de la zona norte de Cataluña.

3 Cuando ello sucede, suele haber una diferencia, sea de la naturaleza del ganado, sea del número de cabezas. Por ejemplo, en la localidad 15, bestiar se dice pref́crentemente si es un rebaño de ganado lanar y ramat si es de cabrio: en el punto 23 la rabera tiene más de siete cabezas y el ramat menos, lo cual tiene una commotación juridica, pues el primero sólo puede pasar por las cañadas y lugares adccuados para ello, mientras que el segundo puede pasar por cualquier parte; cn cl punto 34 , las formas rebaño y ganin comportan también una diferencia numérica: es mayor el primcro que el segundo. De todas formas, los términos cspecificos para referirse a un pequeño rebaño, a una punta de ganado, los homos agrupado ch otro nupa, que no aducimos aqui, como respuesta que son a otra pregunta del chestionario.

- Las formas rebaño y ramat pertenecen a la lengua común, en español y en catalín, respectivamente. I, forma rabera es propia del valenciano y se extiende por las zonas de Candesa y Tortosa (DCVB; Mestre, Voc. Turtosa; SAlVADOR, Foc. Berrassal). Las formas ganado [ganáu] y bestiar no las liemos encontrado documentadas en el sentido preciso de arebaño que adquieren en esta zona: notcmos que en ambas se ha producido el mismo fenómeno semántico. pasando de un valor masivo a un valor colectivo; de no contable a contable. 
estas áreas tienen una configuración distinta de las que acabamos de considerar, como puede apreciarse comparando los dos mapas; los tipos léxicos que aparecen presentan, además, en este caso, una mayor con1plejidad por lo que se refiere a la abundancia de variantes formales; la primera área, que corresponde a la zona castellano-aragonesa, y cuyos línites coinciden con la frontera lingüistica, presenta dos tipos léxicos: chito y racina, pero no la dividimos a su ve\% en dos, porque no tenemos elcmentos de juicio suficientes para poder afimar que ambos se agrupan en sendas áreas diferenciadas ${ }^{1}$; encontramos una segunda área con el tipo singló ${ }^{2}$, una tercera con el tipo bagot ${ }^{3}$, y una cuarta con el tipo carroll 4, que enlazan, respectivanente, con las regiones situadas al norte, al sur y al este de la zona estudiada; obsćrvese que la forma chito, que encontramos en la zona castellano-aragonesa, tiene algunas correspondencias en la zona catalana: gitet en el punto Io $y^{r}$ git $^{5}$ en el punto 25; nótese también la presencia de un tipo léxico minoritario: brot, en las localidacles 27 y 39 .

I5. Son varios los conceptos que dan lugar a situaciones más complejas que cualquicra de las que hemos considerado hasta aliora, sea por interferencia de varios de los tipos de distribución que nos hemos esfor-

I BORno y PAKDO recogen la voz racimo con el significado de «hijucla o parte de una uvan, que es como la hemos documentado en tres de las seis localidades lingülsticamente aragonesas que estudiamos; en ellas, para decir un racimo de uva se dice simplenente $\imath$ ina $\imath v a$, y así la palabra racimo puede pasar a adquirir un valor más específico. No hemos encontrado documentada la forma chilo con el valor especifico que aqui consideramos, sino con el wás genérico de "retoño" o "brote" (MONGe, Puebla de Hijar). Notemos que la forma chito (y rechito) aparece, junto con otros tipos léxicos, entre nuestros materiales correspondientes al concepto "retoño de un vegetal"; asimismo aparecen las correspondientes catalauas git y regit.

2 Singló es uno de los tipos léxicos más geveralizados en catalán para designar cste concepto; asi lo recoge el $D C V B$ con sus variantes singlot, xingló y xinglot.

3 El $D C V B$ recoge la forma abegot, con el significado de "gajo de uva", que nos ocupa, y también con el de "redrojo" (racimo pequeño, todavia vercle cuando se vendimia); en una parte de nuestra zona también coincinen los dos significados de este tipo léxico. No aducimos los materiales correspondicntes al segundo concepto para no interferir el curso de nuestra exposición.

4 I:I DCVI3 recoge esta forma con el significado de "redrojo». Fin BurNis, Fragn se le da una definición ambigua: "penjoll de raim»; igualunente sucede en Casacuberta-Coromines, Parlars äagonesos, donde se define como "gotiun de raỉu", atribuido a Plan, Gistáin y Bielsa (gotim en catalán puede significar "gajo" o "redrojo").

- Git, que no aparece en el $D C V B$, tienc el significado más general de wbrote o retoño de un vegetal" (véase nuestra nota I). Compirese con la forma brot, de idéntico significado más general, que tambićn aparece. 
zado en presentar aquí de una manera aislada, sea porque el crecido niimero de tipos léxicos, o su repartición anárquica, no permite suponer la existencia de unas áreas delimitadas dentro de la perspectiva de la zona que nos ocupa. Presentamos a continuación tres ejemplos suficientemente ilustrativos de cada una de estas dos motivaciones, con lo cual pondremos fin al muestreo que estanos llevando a cabo. Lil primero de cllos corresponde al concepto "guardar" (preguntando concretamente "guardar la ropa en el armario o en un lugar adecuado para ellon); los materiales correspondientes nos of recen una gran diversidad de tipos léxicos, pero un primer intento de interpretación nos muestra que, entre ellos, hay tres que son fundamentales: alzar, repretar y desar, con sus variantes formales correspondientes; lo que ocurre es que, juntamente con ellos, aparecen en las mismas localidades otros de repartición menos uniforme, como recoger, retirar, amagur, rcplegar, aixecar, gi:ardar, además de perífrasis, como poner en el armario, ficar a l'armari, posar a l'armari, echar al arca, que contribuyen a desdibujar las áreas que, de acuerdo con los tres primeros, pueden delimitarse (véase mapa num. I8); cu efecto, podemos distinguir una área en la que aparece uniformemente aliar, en sus diversas variantes fonćticas, otra en la que aparecen distintas variantes de repretar, y una tercera, más reducida, donde apunta el tipo desar; la zona de alzar presenta una continuidad entre el valenciano y el castellano-aragonés ${ }^{1}$; el árca de repretar ${ }^{2}$ se nos presenta como una zona intermedia entre la anterior y la de desar, por lo que se relaciona con los casos que hemos presentado en el $\$$ I3 (mapas I2 y r3), aunque la configuración de las zonas sea distinta; $y$, por último, la zona correspondiente a desar ${ }^{3}$ es un típico ejemplo de término generalizado al este y norte de nuestra zona, pero que apenas supera la frontera administratira entre Tarragona $y$ 'Teruel, de un modo aproximado a lo que su-

1 Aumque en muestros materiales alzar se prolonga por la zona castellanoaragonesa de una manera bastante uniforme, no hemos encontrado referencia kle este tipo léxico en los repertorios aragoneses; BORAO trae la forma alzado con el significado de arobo, hurto $y$, en general, toda substracción maliciosan. La R.tE recogre, entre las accpciones de esta forma, dos que tieneu relación con el significado que consideramos: "7. Recoger y guardar u ocultar alguna cosa. 9. Retirar del campo la cosechan. Garcfi Soriano, Voc. mutsciano la define como "guardaro. Il $D C V B$ incluye al far con este miswo significado, atribuyéndolo al valenciano.

2 Repretar aparece en el $D C V B$, como propio del Maestrazyo, con la definición de ureunir coses disperses amuntegant-les a un lloc». Eu aragonés (véase PARDo) la forma repretar significa eahorraro; la estrccha relación semántica de "guardar" con "aloorrar" puede scr atestiguada con otras coincidencias léxicas.

3 El $D C Y B$ da las formas desar y alesar, sin iudicación geográfica. 
-cede con el caso que hemos tenido ocasión de considerar en el mapa número 6. El hecho de que todas estas circunstancias confluyan en las denominacioves de un mismo concepto origina una situación de una complejidad notable.

Ió. Los materiales correspondientes al concepto "botijo» (mapa número Ig) presentan también un gran numero de tipos léxicos, pero con una distribución diferente. Fin primer lugar cabe destacar el hecho de que, en el caso de "guardan, tres tipos léxicos cubren toda la zona ${ }^{1}$, mientras que todos los demás se hallan superpuestos, conviviendo con los primeros; en el caso que ahora va a ocuparnos no sucede así, pues, hechas dos salvedades (los puntos 34 y 35) el concepto "botijo" tiene una sola denominación en cada localidad; con todo, observamos que con tres tipos léxicos se cubre la mayor parte de la zona, quedando los demás localizados sobre todo en las partes periféricas. I, a mayor frecuencia corresponde a los derivados del radical cantar- o canter-, que presentan la forma cantarica en la parte castellano-aragonesa, y la forma canterella 2 en la parte catalana; cl tipo pitxella ${ }^{3}$ se encuentra en ocho localidades, y el tipo txorrillo (chorrillo) ${ }^{2}$ en otras ocho; tanto unas como otras no se hallan dispersas o entrenczcladas, sino que forman agrupaciones no

1 Iray que liacer la salvedad de que en el punto 39 no aparece ninguno de los tres tipos principales, circunstancia que aprovechamos para hacer notar que aixecar, que aparece en cste punto y en 27, aparte de este significado especifico, coincide también con alşar en su significado búsico y genérico de "levantar", lo cual puede llevarnos a una serie de consideraciones semánticas que, de momento, escapan a nuestra intención.

2 I, a forma canterella aparece en el $D C V B$ con este significado, como propia del valenciano; también aparece canterell, referido a IAlucena y Castellón. El ALC (mapa 395) registra canivclla cil Maella y canterell en Gandesa.

3 Las distintas referencias que hemos encontrado de pitxella (o pichella) son designaciones de otras vasijas distintas del "botijo»; sólo en el ALC (mapa 395) aparece pitxell con este significado en la localidad leridana de vilix. La RAE du la forma pichella como propia de Aragón, con el significado de "jarro o vasija para medir vino, y cuya calida es por térunino medio la mitad de un litron; taubién recoge pichel cono nombre de una vasija de estaño. Lin PAkDo encontramos pichela con el significado de "jarro con pico acanalado para servir vino»; y en Cor,I, y Ar'munis, boces La Litcra, pichclla eqquivale a "vasija de medio jarro de cabida". Lil $D C V / 3$ (s. v. pitxella) nos da dos definiciones: "1. Recipient de terrissa de forma quasi ovalada, amb) una ansa, que serveix per a treure vi i abocarlo o beure'l a galet (Andorra, Pallars, Ribagorşa, Conca de Tremp); cast. jaria. 2. Recipient de forma semblant a l'anterior, usat per a treure, abocar i beure aigua (Aitona, Priorat, Micquinensa)."

4 En relación con esta forma sólo hemos hallado el vocablo chorrete (LLATAS, Villar del Arzobispo), y ann con un significado algo distinto del que nos ocupa: " "ćmtaro con un pitón en la panza para beberi (véasc dibujo en dicha obra). 
totalmente compactas, pero si bastante coherentes. I.os otros tipos léxicos se reparten a base de una o dos localidades cada uno; son los siguientes: txurntll y txurumbell ${ }^{2}$, barral y barrala ${ }^{2}$, reixat ${ }^{3}$, marraixó 4 , boteja y butijo ${ }^{5}$. A pesar, pues, de la diversidad de denominaciones, se observa alguin indicio de pequeìas áreas mejor o peor delimitadas (cuy'os línites. 116) hemos scivalado con trazos cll cl mapa, porque nos ha parecido que cn cste caso se aprecian mejor simplemente con los signos convencionales empleados). Sin embargo, no sucede igual, o sucede en un grado muclio menor, con algunos otros conceptos que presentan todavía mayor nimero de formas léxicas distintas; ello suele ocurrir en casos en que las denominaciones pretendeu ser descriptivas, metafóricas, o bien responden a algin otro tipo de fenómeno motivador. Un ejemplo notable, que es el de mayor complejidad que hemos encontrado, a pesar de que falta la respuesta en varias localidades ${ }^{\circ}$, lo tenemos en los nombres que se dan a la libélula (mapa num. 20); salvando ciertas peculiaridades fonéticas o alteraciones formales, cuyo detalle puede observarse en las.

1 I,as formas txurull y txurumbell sólo las hemos encontrado docunentadas. cil cl $D C V B$; referidas únicamente a Morella, con cl siguificado de «botijo de dos. pitonest.

2 La forma barral tiene, tanto en catalán como en aragonés, diversos significados referidos a varios tipos de recipiente (véase nuestra nota $\mathrm{r}$, p.24r). Cou al significado de "botijon está recogida en BARNIr, Fraga y en CORBLLLA, Voc. Ribagorza. I a forma barrala aparece, con este significado, en el $D C V B$, como. clocumentada úmicamente en la localidad de Arnes; nótese que nuestros materiales dan para Arnes la forma pitrella.

3 La forma reixat aparece, con este mismo siguificado, en ALC (urapa 395) sólo en la localidad de Calaceit, coincidiendo con nuestros materiales; ésta es la. única referencia que recoge el $D C V B$.

- La forma marraixó aparece documentada en Ulldecona, Vinaroz y Benasal (segúu el $D C V B$ ) con el significado de abotijo de dos pitones, de tierra o. de metaln; también aparece en el $D C V B$ la forma marraixa, con el siguificado. de "damajuana, bombona", documentada en diversas localidades valencianas. Fin Bunfa, loc..aragonés, cucontramos marracha con el significado de "cúntaro"; y en Garcí SordaNo, Yoc. mirriano, marraja, con los significados de "garrafa". Y "lamajuana".

3 La forma boteja aparece en BOR^o con el significado de "botija", y la RAE la recoge, como propia de Aragón, con el significado de «botijon. In $\Lambda$ LVAR, Cucvas di Cañart y en BADì, Biclsa, hallamos la forma botejon, con el mismo siguificado. 'También con el significado de abotijon, el $D C V B$ nos da la forma botija, cono propia de V'alencia, y el $A L C$ (mapa 395 ) presenta en la localidad de Fonz la forma botilla.

- Fin las localidades snñaladas con un signo de interrogación los informadores, a pesar de identificar cl insecto, no han podido atribuirle ningún nombre especifico. 
transcripciones del mapa, han aparecido las siguientes denoninaciones : míllico, doctor, andren, petín, gitano, avión, aeroplano, vicari de bassa, cuc de les basses ${ }^{2}$, cuc plovedor, taval, tabano, tavan (o taval) d'aigua, cavallet, cavall (o cavallet) de serp, cavallet de sèquita, relicari, relicario, teixidor, sangrador, saiter, rodadit, esintitxidor, pixatinters, escopeta, xopaculs.

I\%. Fin resumen, los principales modelos de repartición del léxico que hemos olsservado en esta zona pueden ser agrupados del siguiente modo:

I. ${ }^{\circ}$ Uniformidad en toda la zona ( $(\S)$.

2. División en dos áreas léxicas ( $\$ \S 9, I C$, y II).

3. División en tres áreas léxicas ( $\$ \$ I 2$ y $I: 3)$.

$44^{\circ}$ División en cuatro áreas léxicas (\$§ I 4 , I5 y I6).

$5 .^{\circ}$ Iromiscuidad parcial o total (\$\$ I5 y I6́).

En los casos de uniformidad hemos dintinguido los que, además de la coincidencia de tipo léxico, presentan una identidad en su forma de expresión, de aquellos que, conservando la unidad de tipo léxico, ofrecen divergencias en su forna fónica, sea por circunstancias debidas a una diferencia en los sistemas fonológicos de las liablas en cuestión, sea por los dispares resultados a que ha dado lugar, en distintas zonas, la erolución fonética a partir de un mismo étimo. Fintre los casos de existencia de dos áreas con un tipo léxico distinto en cada una de ellas, por una parte hemos destacado aquellos conceptos, ciertamente numerosos, en los cuales el límite entre las dos áreas coincide con la frontera lingüística; $y$, por otra parte, hemos atendido a la existencia de abundantes límites léxicos no coincidentes con ella, entre los cuales hemos destacado los que determinan áreas marginales en el ámbito de nuestra zona, con penetración en ella de formas léxicas propias, fundamentalmente, del valenciano o del catalán oriental. Fin cuanto a los casos de dirisión en

1 In los repertorios consultados sólo hemos poclido documentar algunas de estas denominaciones: cavall de serp aparece en el $D C V B$ atribuido a Bagá, Plana de Vic y Viladrau (y en Mallorca y Menorca como nombre de la "mantis religiosa); la misma forma aparece en el $A L C$ (mapa 757 ) localizada en las zonas de Barcelona, Gerona y norte de I,érida; cavallel se encuentra, según el $A L C$, en Morella, Ulldecona y Sagunto; también según el $A L C$, rodadits es propio de Calaceit, Tortosa, Gandesa y Flix, y tixeire (que podemos poner en relación con nuestro teixidor) aparece en Sallagosa (rosellonés). De entre los demás nomibres, muchos se explican por la forma del insecto, por su tipo de vuclo, por el medio en que vive, ctc. No cxcluimos la posibilidad de que, asi como en algún caso no han acertado a hallar el nombre del insecto, alguna de las respuestas sea fruto de la confusión con el de otros insectos más o menos relacionados con éste.

2 Il vocablo cuc, que en la lengua general significa "gusano", se emplea en esta zona para designar ciertos tipos de insectos de um modo inespecifico, $y$, en principio, cualquier insecto, o animal semejante, que tenga un nombre especifico poco generalizado. 
tres áreas léxicas, hemos partido de la mínina área aislada, que se presenta con una forma discrepante en el límite entre otras dos, para ir considerando casos de áreas mayores, hasta llegar a la presentación dezonas internicdias no propiamente aisladas. Ira existencia de casos que -presentan nuestra zona dividida en cuatro áreas léxicas lia quedado patente cu dos cjemplos distintos, que presentan diversos tipos de configuración de estas áreas. $Y$ ași hemos llegaclo a ejemplificar el tipo de repartición en que prácticamente no se pueden establecer áreas, a causa de la confluencia de una gran cantidad de denominaciones, hasta el punto de que son muy pocas las que se repiten en varias localidades; cabe decir que estos casos no son abundantes, por lo menos entre los materiales que hemos recogido.

IS. Con los distintos ejemplos que hemos considerado creemos haber dado una idea, intencionadamente muy esquemática, de las posibilidades y de los resultados del trabajo que estanios realizando. De todas formas, en algún momento hemos tenido ocasión de comprobar cómo pueden complicarse estas distribuciones sólo por combinación de dos de los tipos simples que hemos considerado (véase, por ejemplo, mapa número II, $\S$ I2), o bien por confluencia de varios tipos léxicos en una misma localidad (véase, por cjemplo, unapa núm. 6 , $§$ II, y mapa número $18, \$ 15)$. Cuando publiquemos todos los materiales obtenidos, debidamente confrontados, podrá observarse que la realidad es mucho más compleja que lo que se deduce de este artículo; sin enbargo, nos ha parecido que en esta noticia informativa debíamos hacer un esfuerzo por presentar aquellos casos que aparecieran como más simples dentro de cada uno de los tipos de repartición geográfica del léxico observados.

\section{Joanuín Rafei, Fon'ranals}

\section{SigLAS Y ABREVIATURAS BIBLIOGRÍFICAS}

AFA: Archivo de Filologia Aragonesa, Zaragoza.

$A L C$ : Véase nota $\mathrm{x}, 1) 233$.

$A L D C$ : Véase nota 5, p. 233 .

ALPI: Atlas lingiïistico de la Pcninsucla Iberica, Vol. I, Madrid, C. S. I. C., 1962.

Alvar, Cuevas de Cañart: M. Alvar, El habla de las Cquevas de Cañart, AFA, III, I950, pp. IS $\boldsymbol{T}_{\mathbf{T}} \mathbf{2 3 9}$.

AIVAR, Salvatierra: M. AI,VAR, Notas lingïisticas sobre Salvatierra y Sigüés (Valle de Esca, Zaragoza), A FA, VIII-IX, 1956-59, pp. 9-63.

AMCILR VII: VII Congreso Internacional de Lingǘstica y Filologia Románicas, Univcrsidad de Barcclona, 7-10 abril de 1953. Tomo II, Actas y Memorias. Publicado por A. BAdiA, A. GruarA, F. UdINA, Barcelona, I955 (BDE, XXXIII, 1954-55 y XXXIV, I955-56). 
AORLL: Anuari de l'Oficina Romànica de Lingüistica i Literatura, Barcelona, Biblioteca Balmes, r928-1934.

ARNAL, Voc, alto-aragonés: P. ARNAL CAVERO, Vocabulario del allo-aragonés (De Alquezar y pueblos próximos), Madrid, C. S. I. C., I944.

BADfA, Bielsa: A. BADfA, El habla del Valle de Bielsa, Barcelona, C. S. I. C., 1950. BADfA, Voc. aragonis: A. BADís, Contribución al vocabulario aragonés moder20, Zaragoza, C. S. I. C., I948.

IBARnis, Iiraga: I'. I3ARnits, Del catuli de Fraga, BDC, IV, I9I6, pp. 27-45. $B D C$ : Bullleli de Dialectologia Catalana, Bareclona, Institut d'Fistudis Catalans, I9r3- 1936.

BDE: Bolctin de Dialeclología Española. Abadia de Sau Cugat del Vallés (Barcelona).

Borno: J. Borno, Diccionario de voces aragonesas (véase nota 3. p. 233).

CASACUmirita-Corominte, Parlars aragonesos: J. M. a dE CASACUnierta \& J. Conominjss, Naterials per a l'estudi dels parlars aragonesos, BDC, XXIV, I936. páginas $\mathrm{I}_{5} \mathrm{~S}-\mathrm{I} 83$.

Corr, y Arrabis, Voces La Litera: B. Col, y Arrabis, Voces usadas en la comarca de La Litcra, en Borso (véase).

Conmist, Voc. Ribagorza: J. CoRmints, Vocabulurio de Ribagorza, BDE, XXXVIII, rg62, pp. \&g-131.

C. S. I. C: Consejo Superior de Investigaciones Científicas.

DCVB: (Véase nota 2, p. 233).

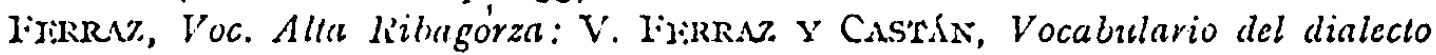
que se habla en la Alla Ribagurza, Madrid, r934

Garcí Soriano, Voc. murciano: J. Garcfa Sorrano, Vocabulatio del dialecto murciano, Madrid, I932.

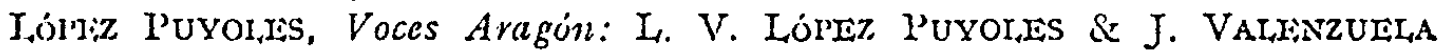

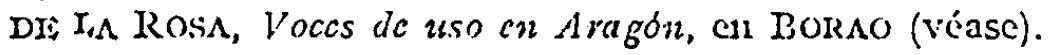

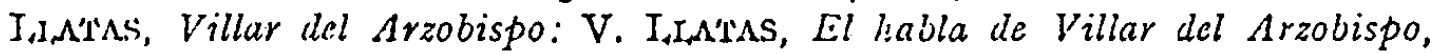
2 Vols. Valcncia, 1959.

Mestres, Voc. Torlosa: F. Mesires, Vocabulari calalà de Tortosa, BDC, III, I9I5, pp. 80-II4.

Mongr, Puella de Hijar: T. Monge, El habla de la Puebla de Hijar, RDyTP, VII, I95I, pp. 187-24I.

PALIAkís, Voc. Penarroja: M. PALIARís, Vocabulari de Penarroja, $B D C$, $\mathrm{XI}$, I921, pp. 69-72.

PARDO: J. PARDO AȘSO, Nuevo diccionario elimológico aragonés (véase nota 3 , página 233).

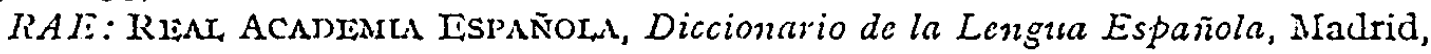
Decimonovena enlición, r970.

RI)yTP: Revisia de Dialectologia y Tradiciones Populares, Madrid, C. S. I. C. IFFI: Revista de Filologia Española, Madrid, C. S. I. C.

RLR: Revue de Linguistique Romane, Lyou \& Paris.

Sarvador, Voc. Benassal: C. Sarvauor, Petit Vocabulari de Benassal, Miscel-lània Fabra, Buenos Aires, 1948, pp. 242-263.

Tresor: A. Griern, Tresor de la llengua, de les tradicions $i$ de la cullura popuslar de Catalinzya, Barcelona, is tomos, publicados entre 1935 y 1947.

Viny, I'aralelismos: J. Vriny, Parulelismos lexicos en los dialectos catalanes, RFI; XIII, I958-59 (1960), pp. 9I-149, y XIIII, I960 (196I), pp. II7-202. ZRPh: Zeitschrift für romanische Philologie, Halle. 


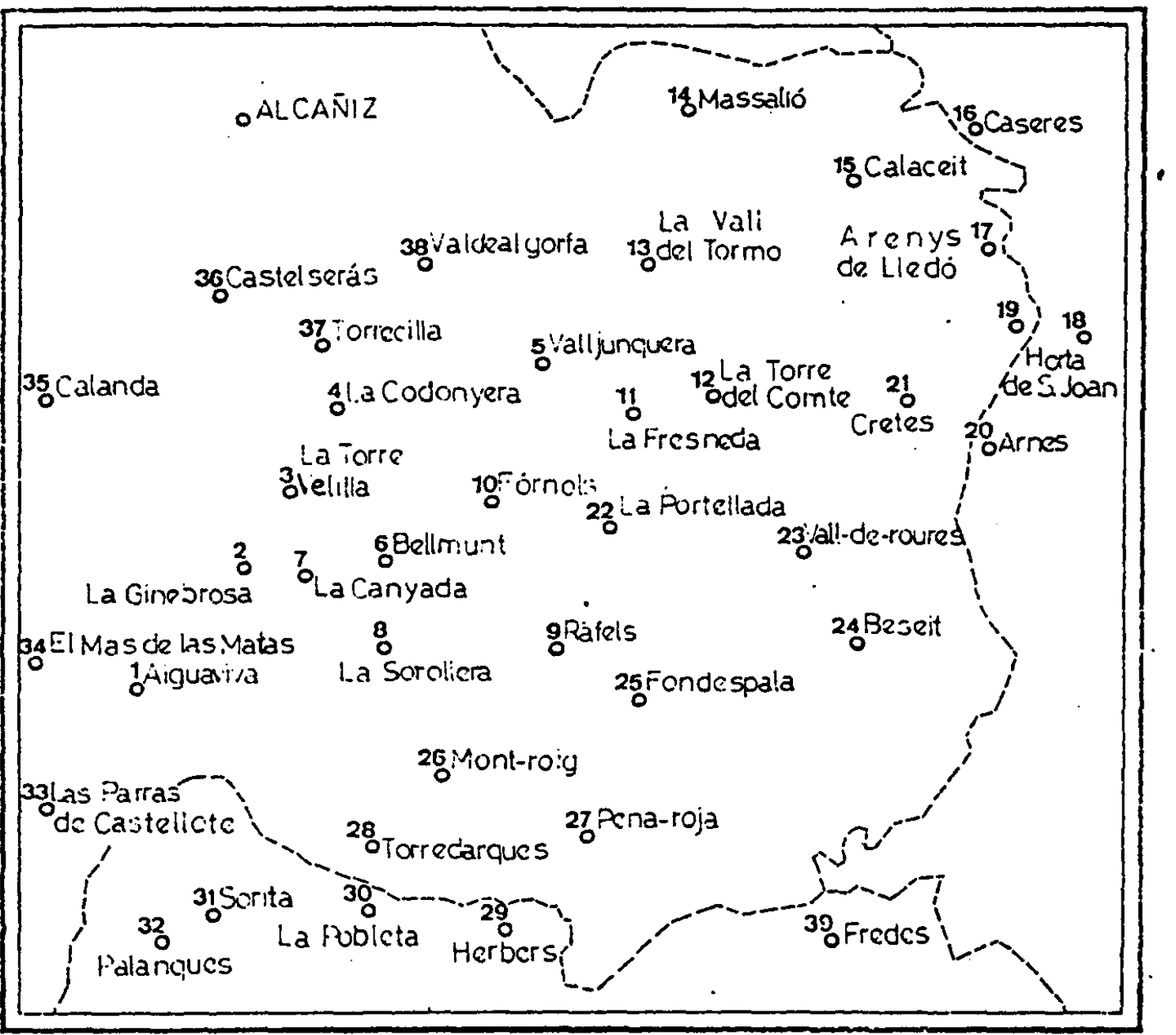

Mapa $n .^{\circ}$ I 


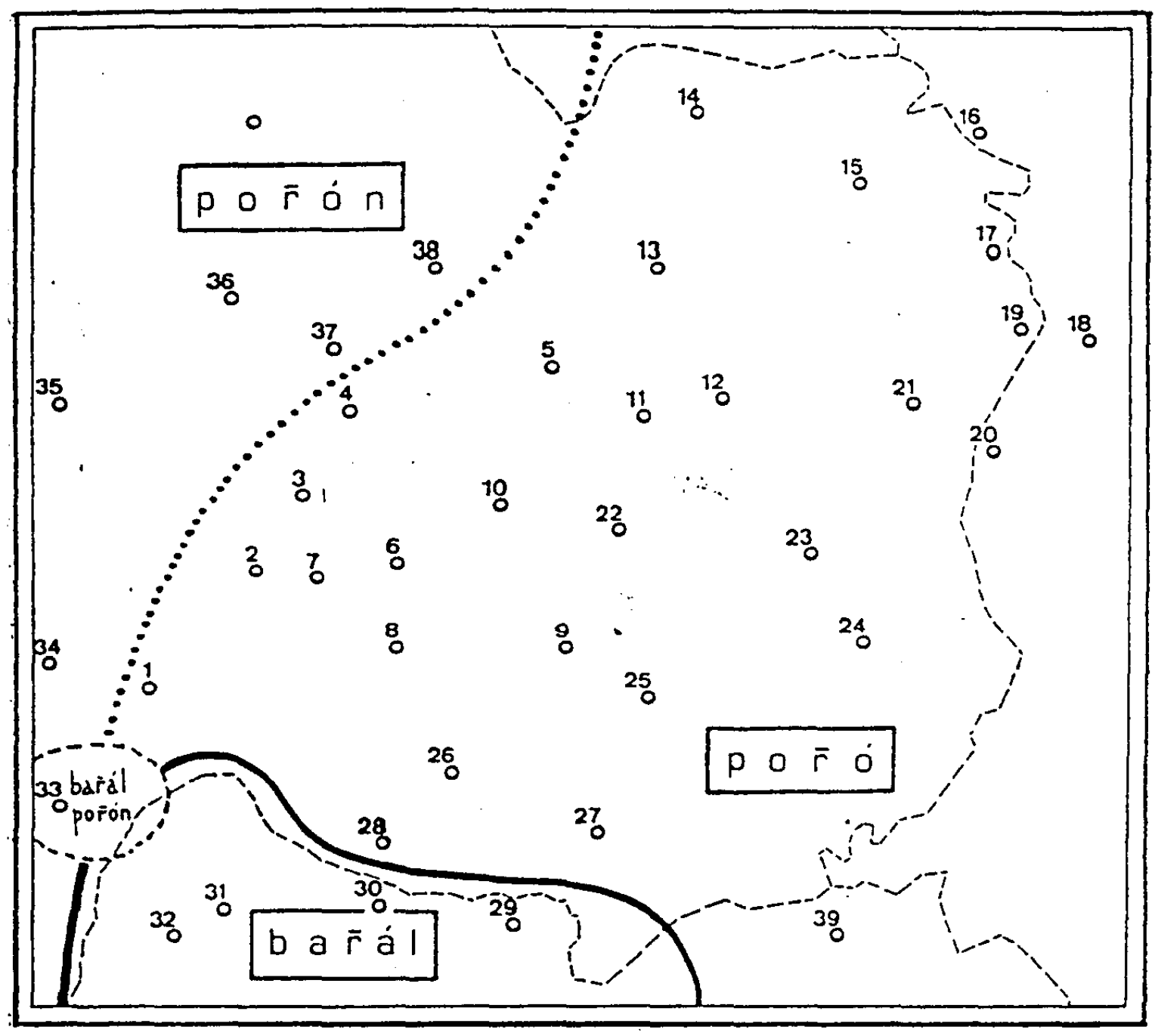

Mapa $n .^{\circ} 2$ 


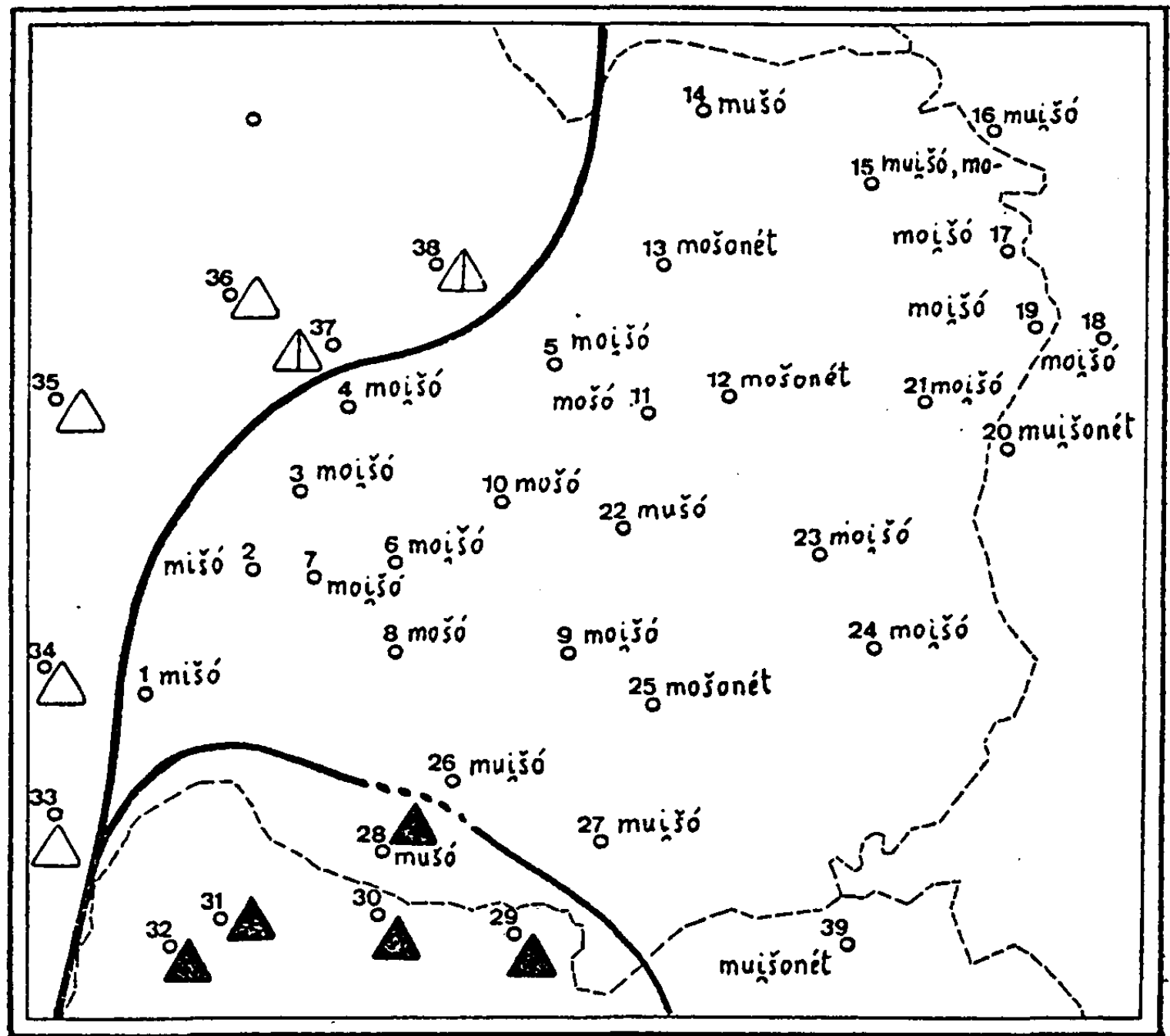

$$
\begin{aligned}
& \triangle p \text { á } x \text { a } r \text { o } \\
& \triangle \text { p a } \times \text { á } r o \\
& \therefore \text { p a } r \text { d á } 1
\end{aligned}
$$

Mapa n.॰3 


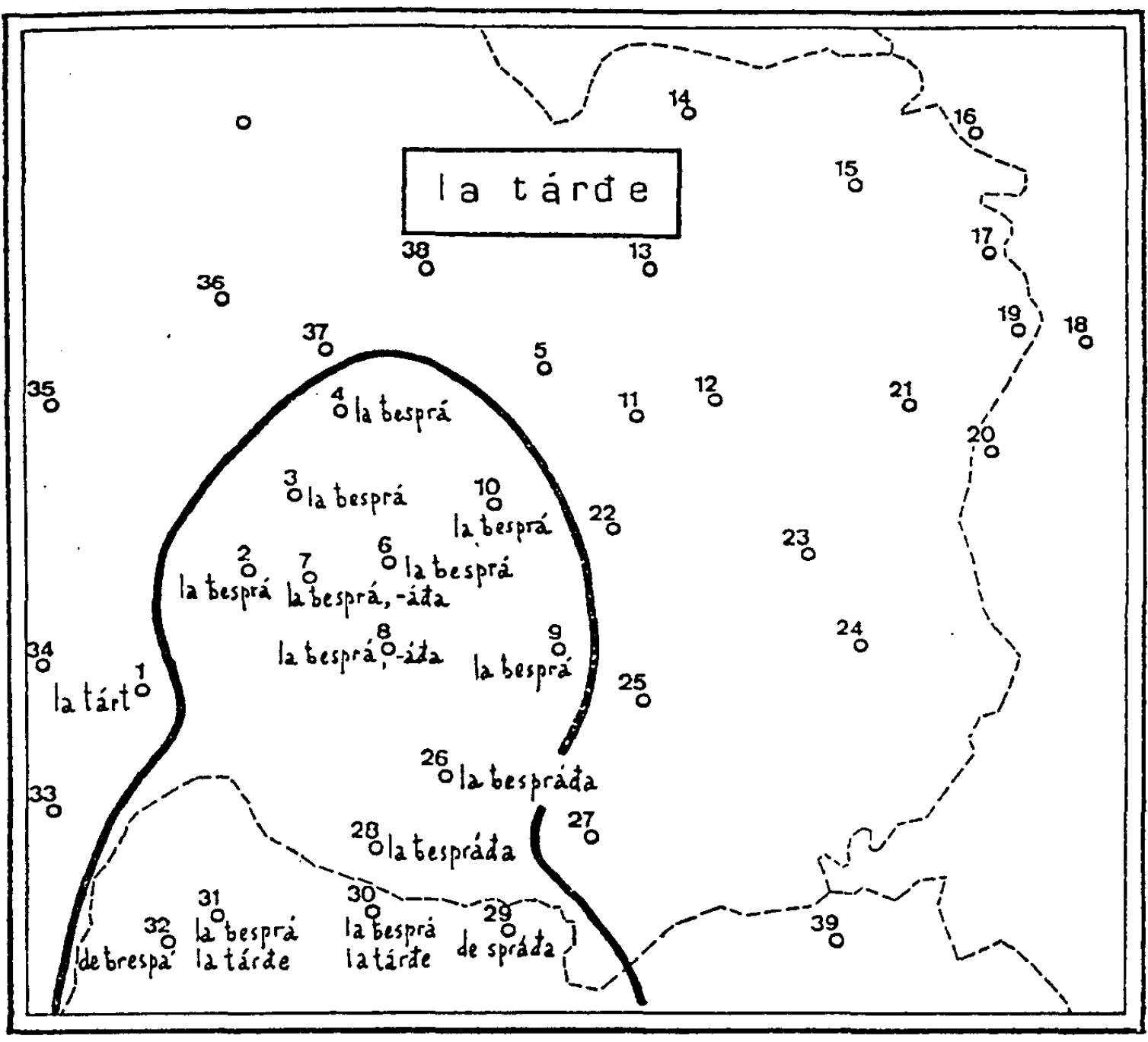

Mapa $\mathrm{n}^{\circ} 4$ 


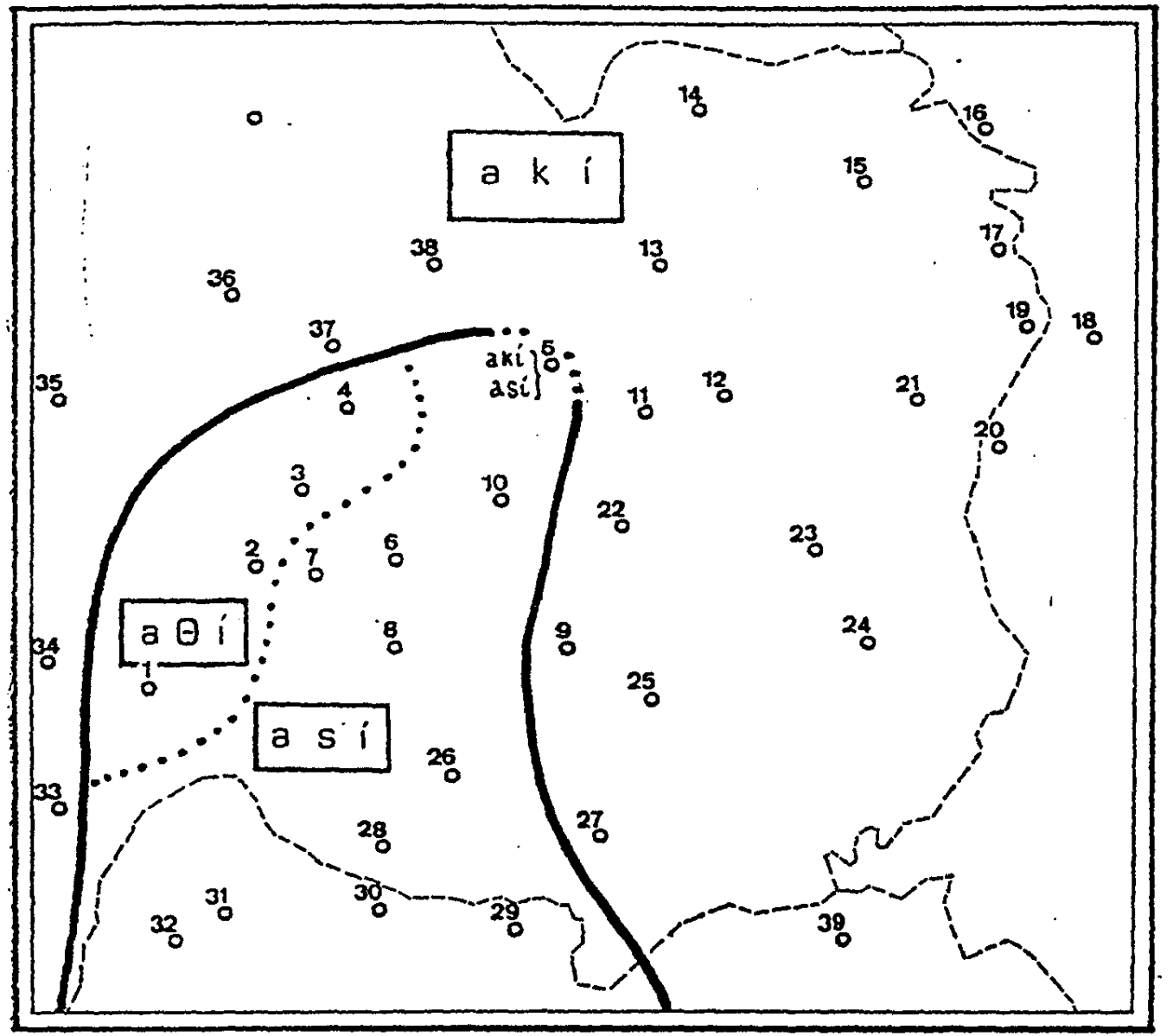

Mapa $\pi .^{\circ} 5$ 


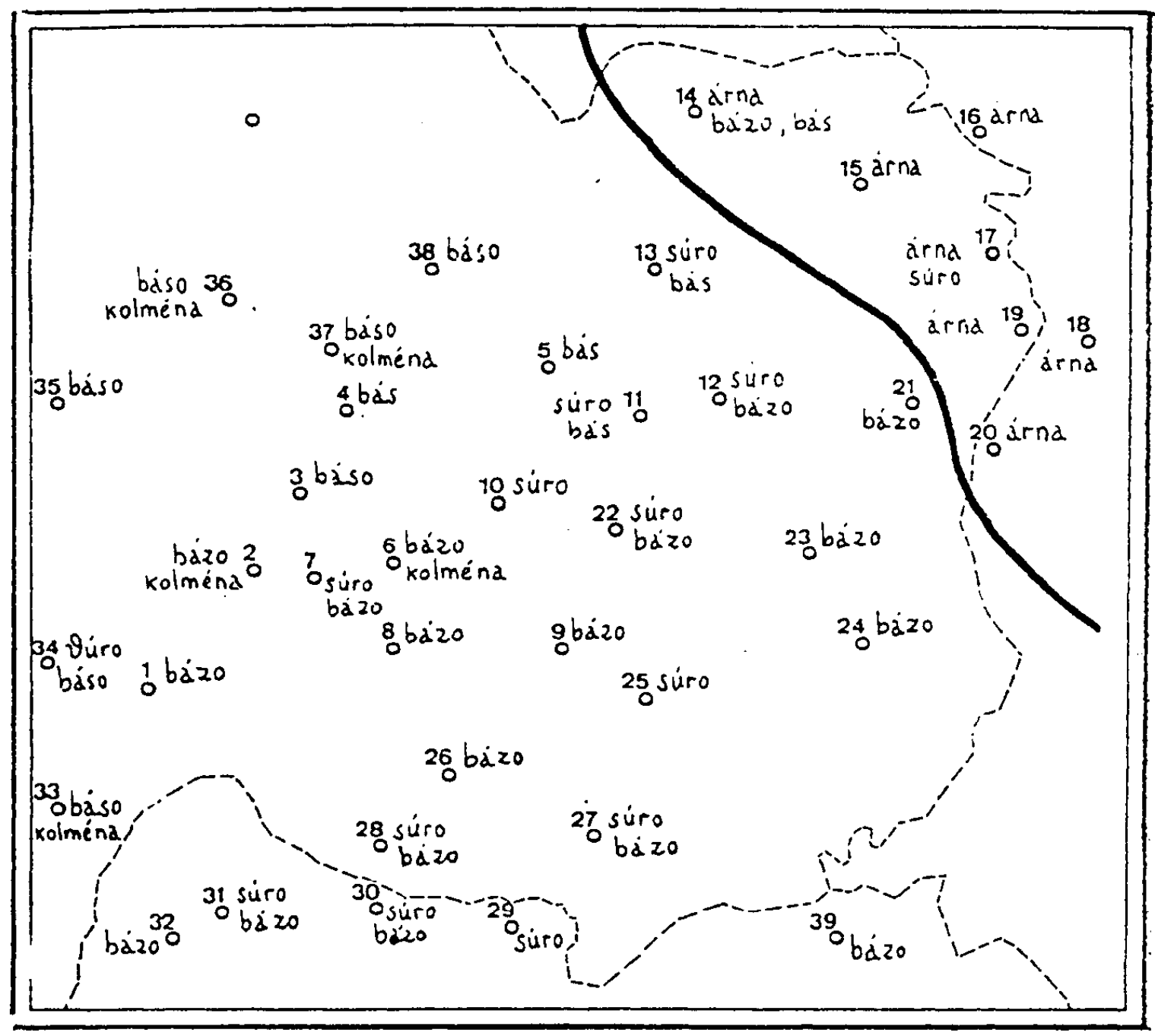

Mapa $n .^{\circ} 6$ 


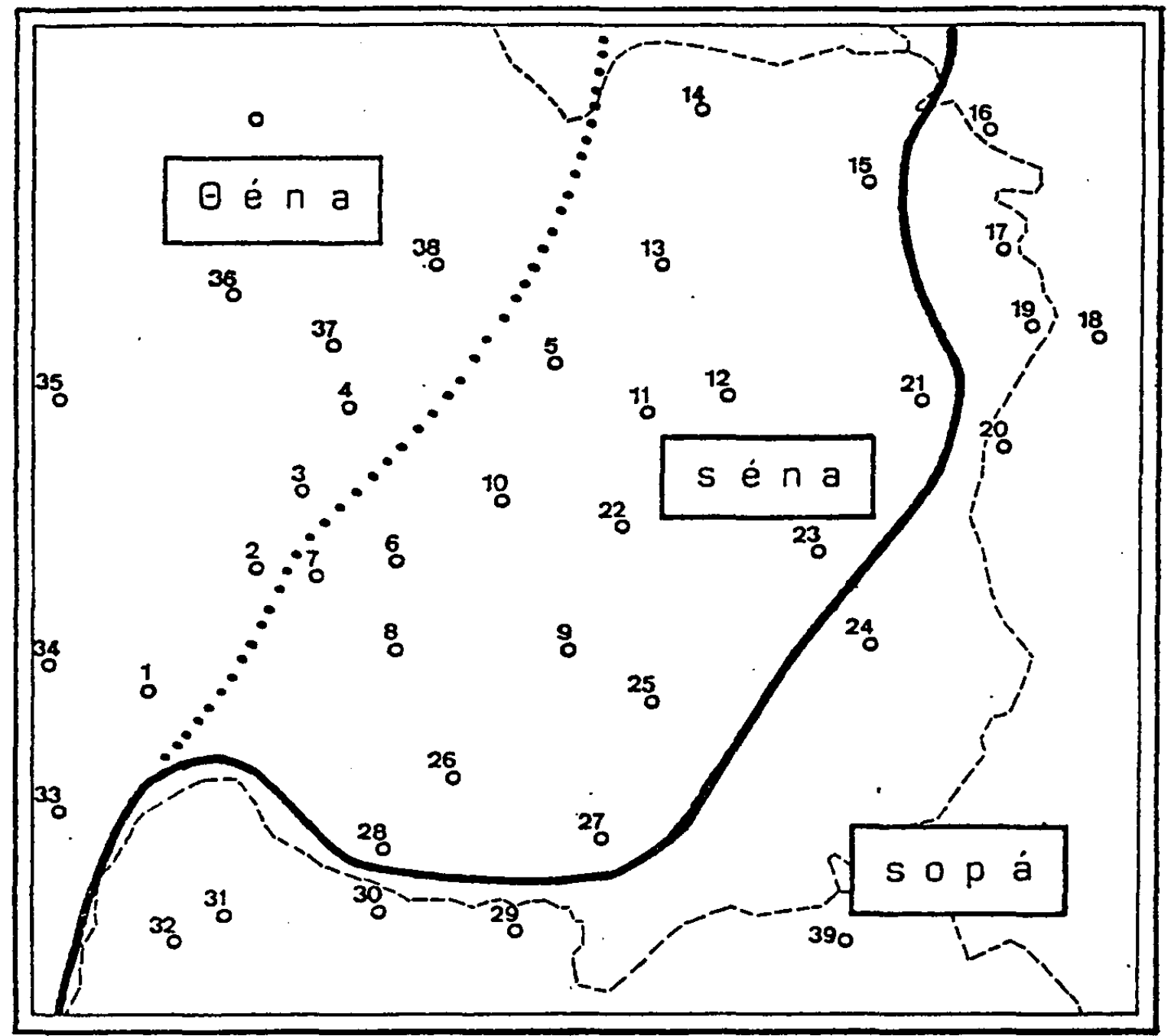

Mapa $\mathbf{n} \cdot^{\circ} \mathbf{7}$ 


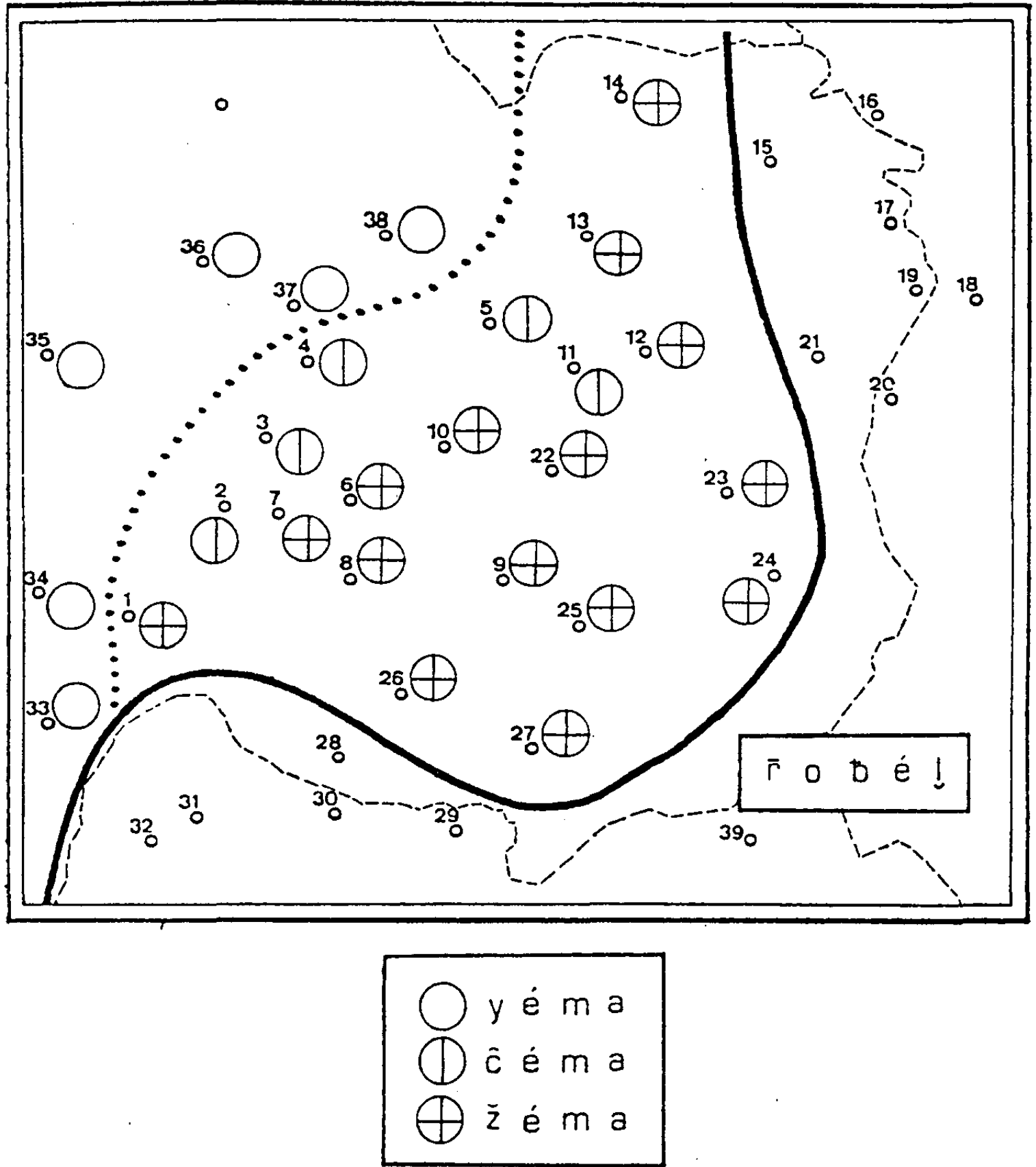

Mapa n. ${ }^{\circ} 8$ 


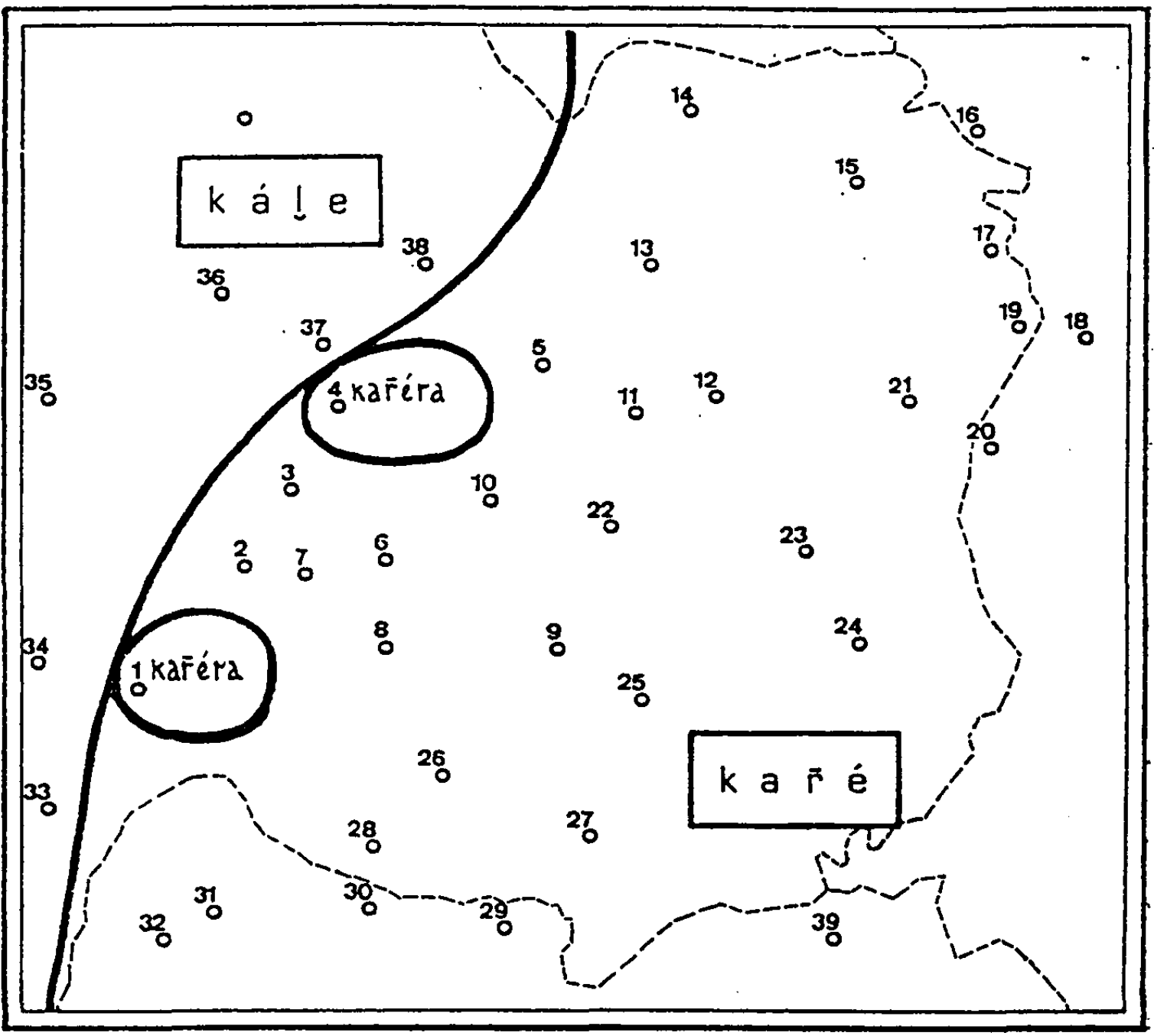

Mapa n.॰9 


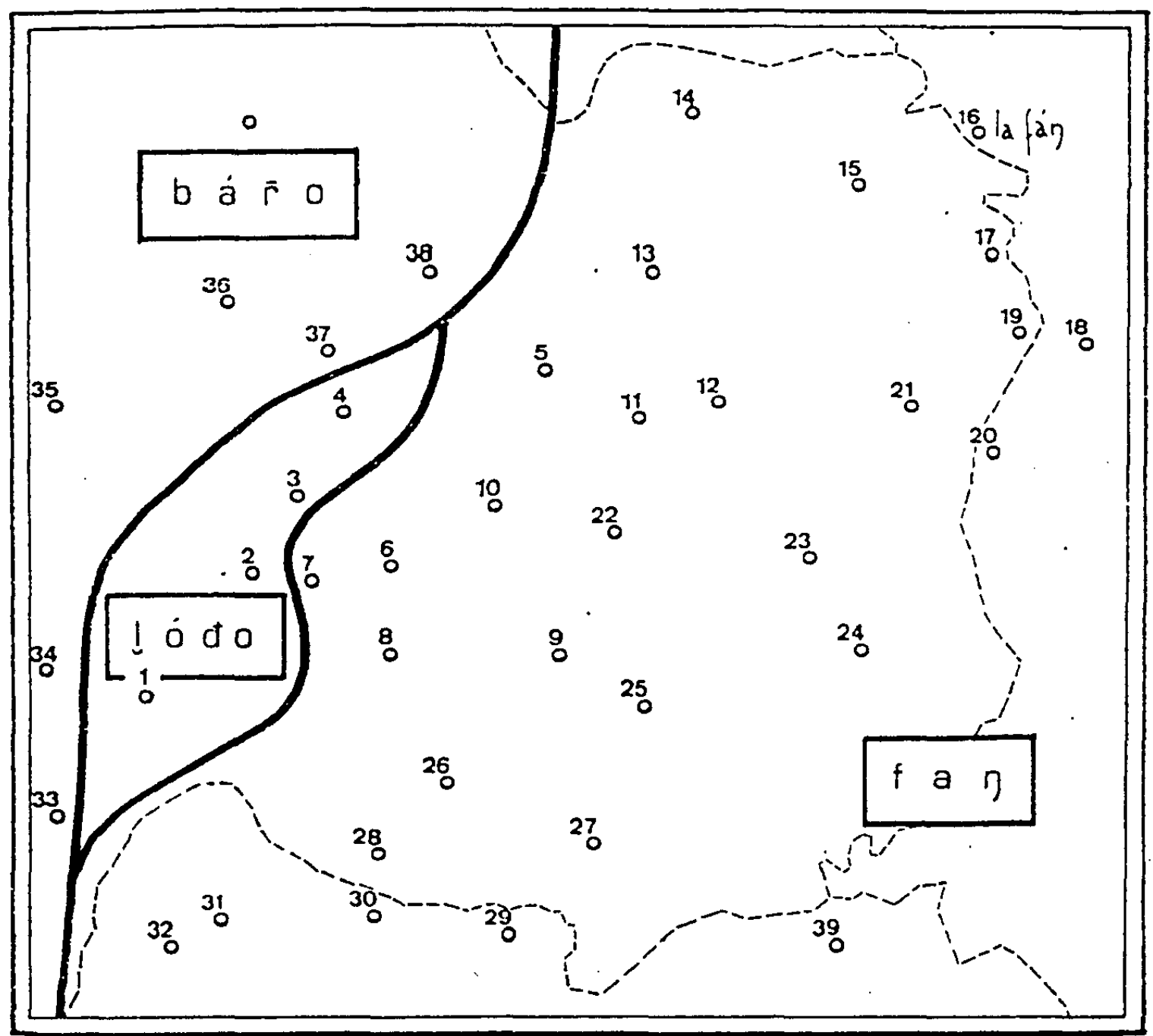

Mapa n. $0^{\circ}$ Io 


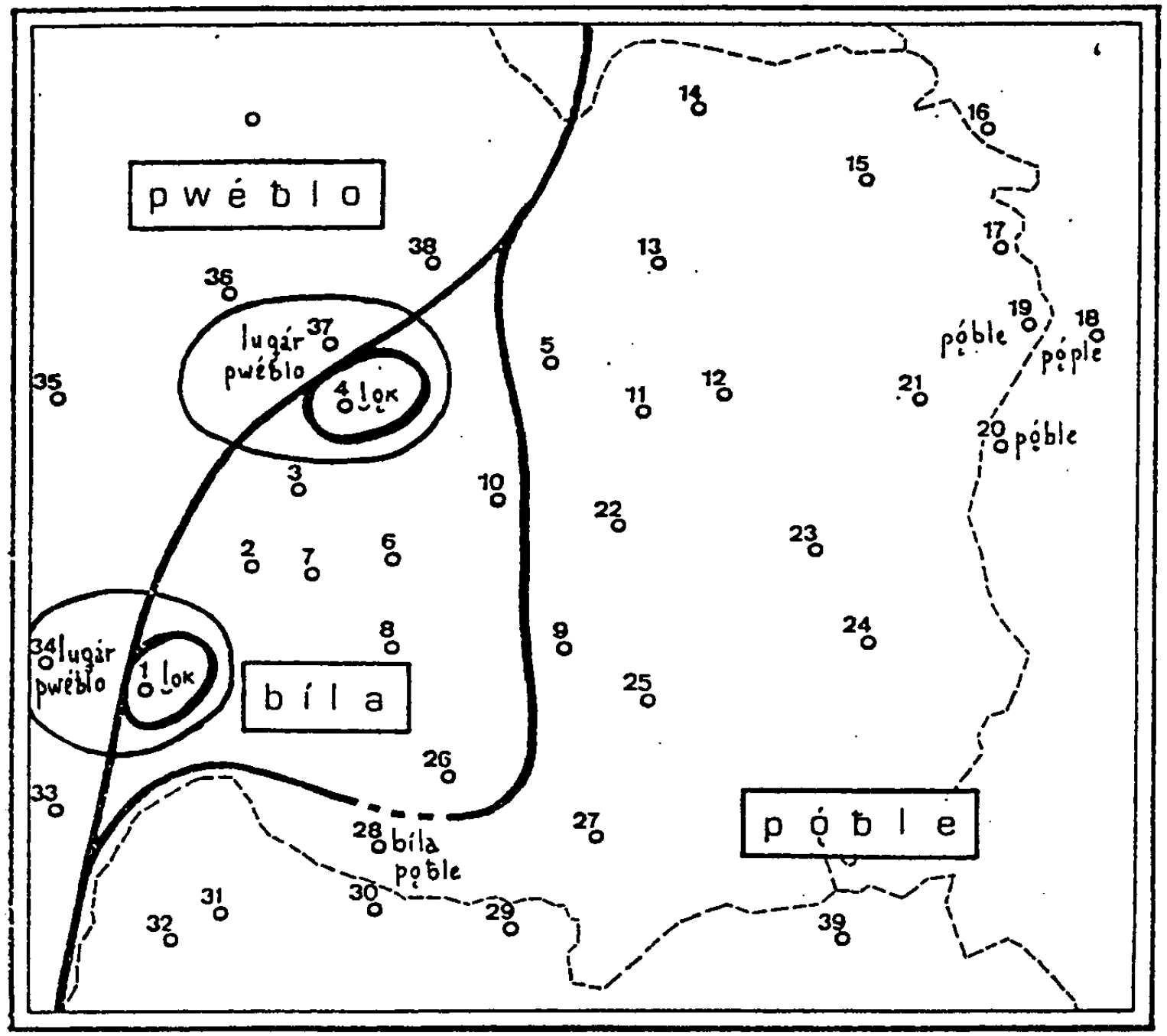

Mapa n. ${ }^{\bullet}$ II 


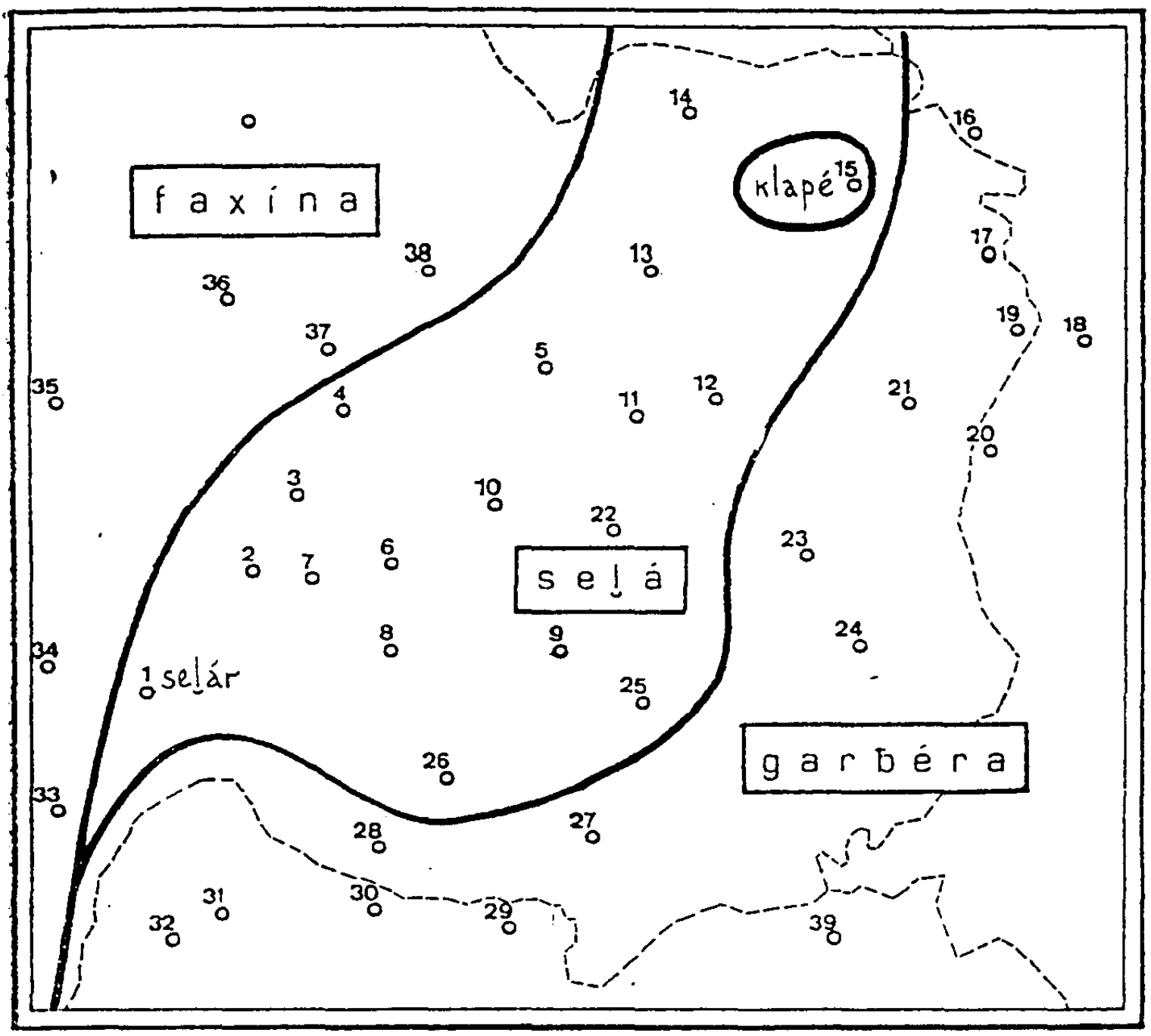

Dfapa $\mathrm{n} .^{\circ}$ I2 


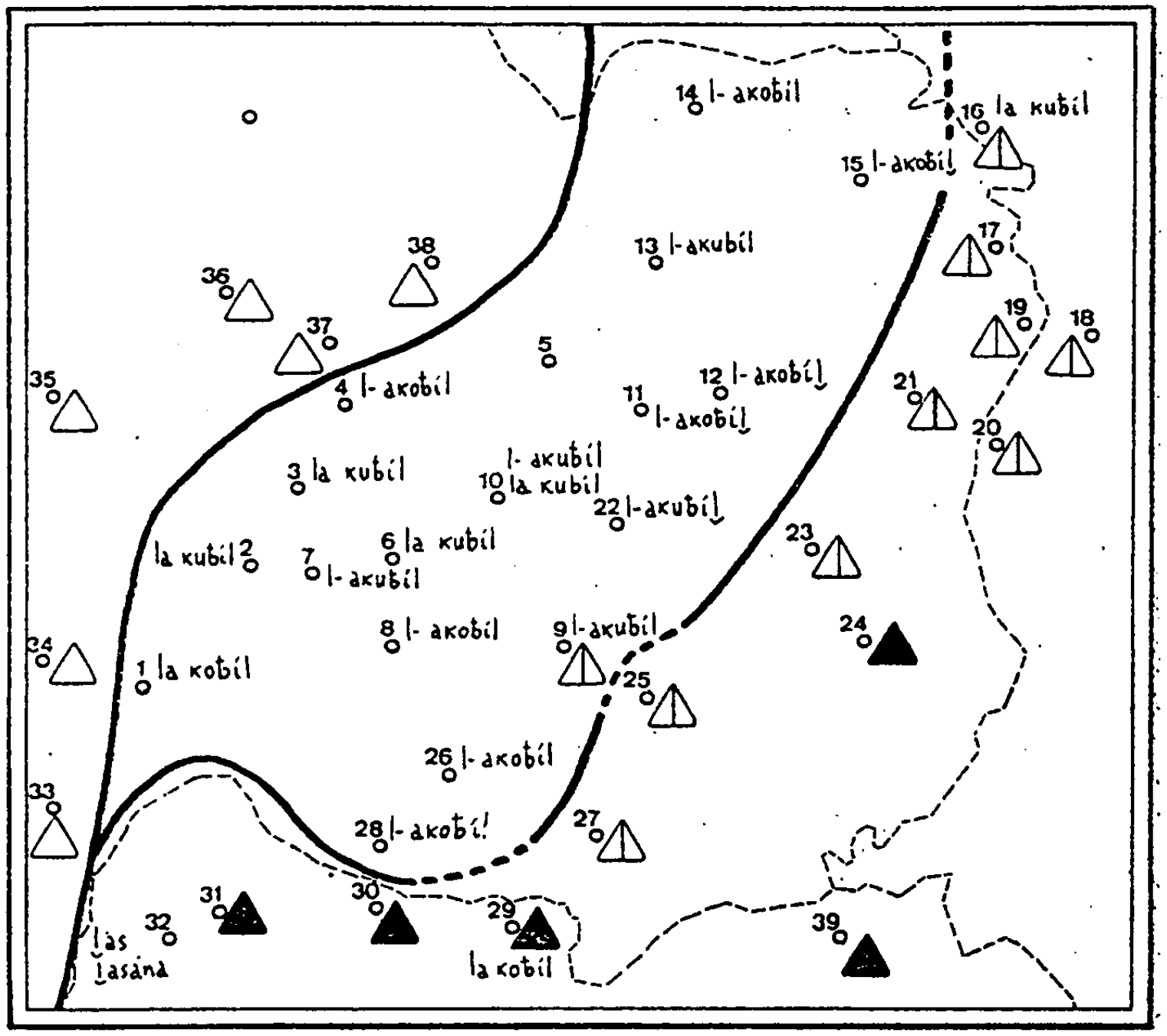

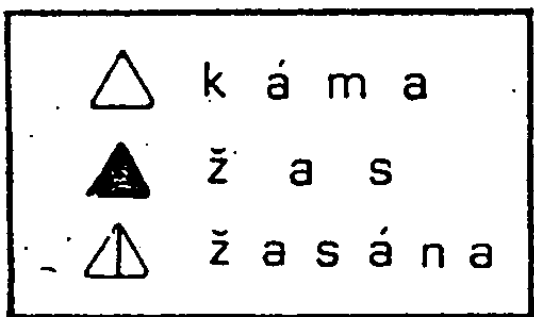

Mapa $n^{\circ}{ }^{3}$ 


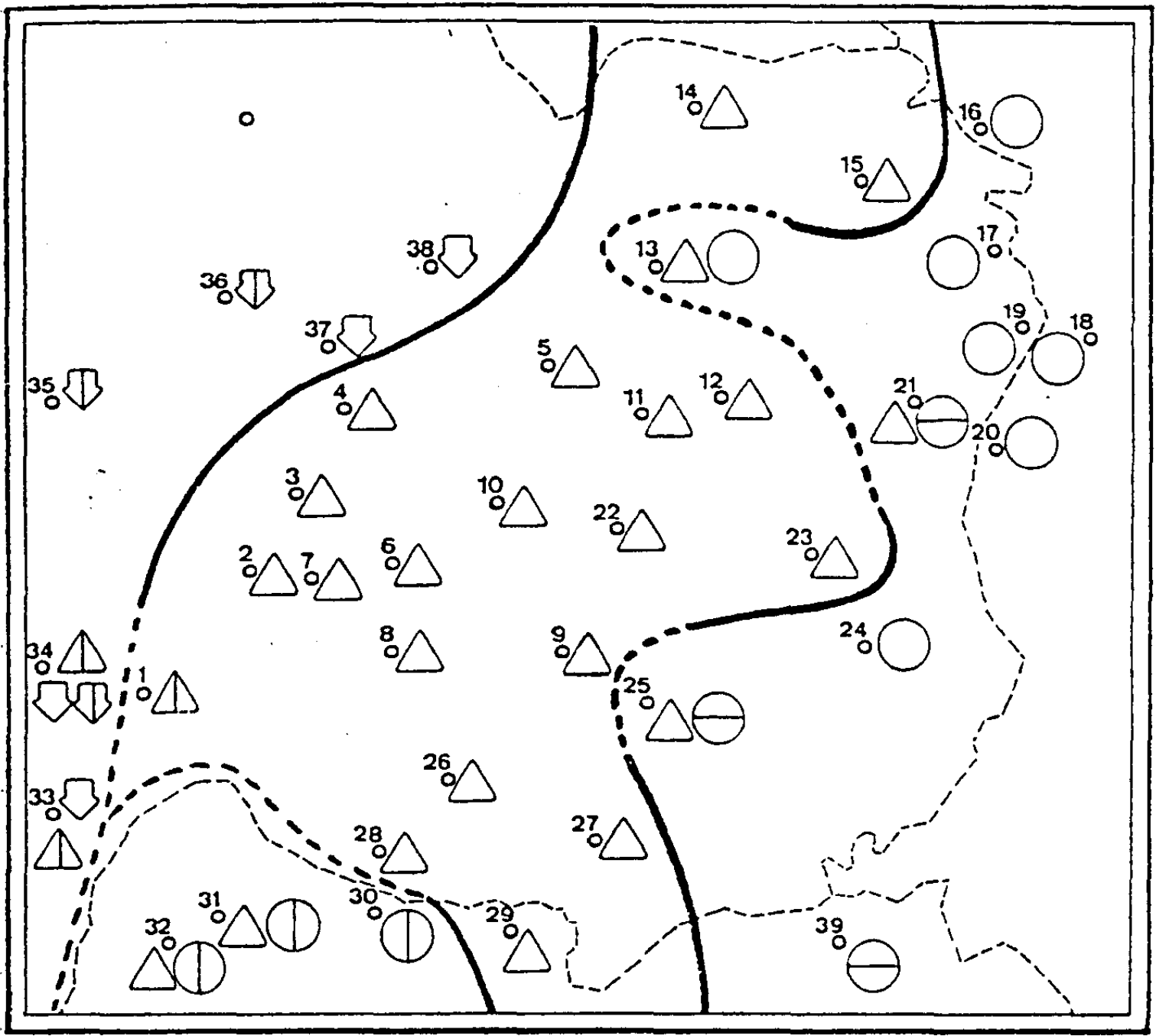

$\checkmark$ méđiko $B$ medíxo

$\triangle$ dotó $\triangle$ dotór

-méže méže $\oslash$ méĉe

Mapa $n .^{\circ} x_{4}$ 


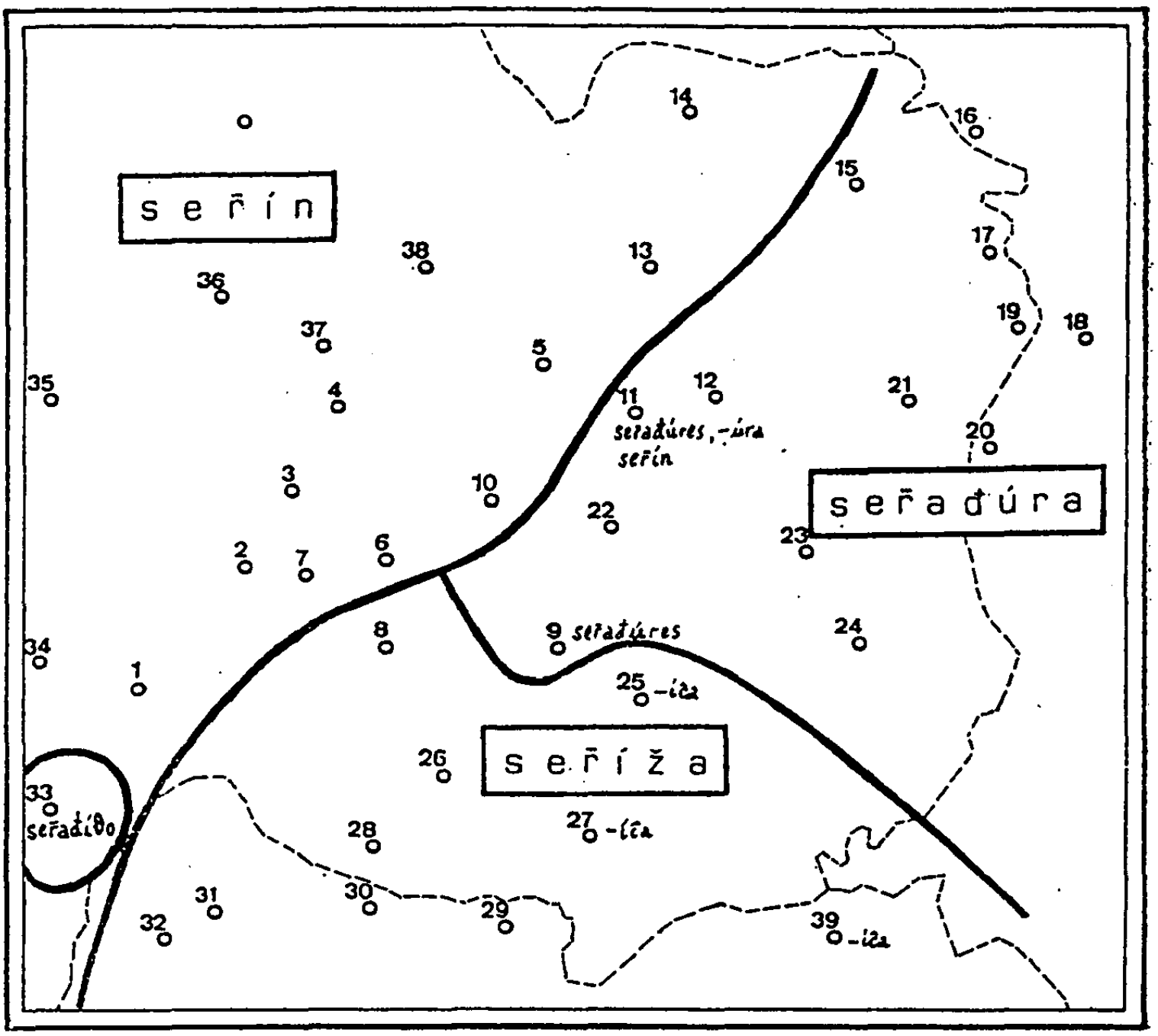

Mapa $1 .^{\circ} x_{5}$ 


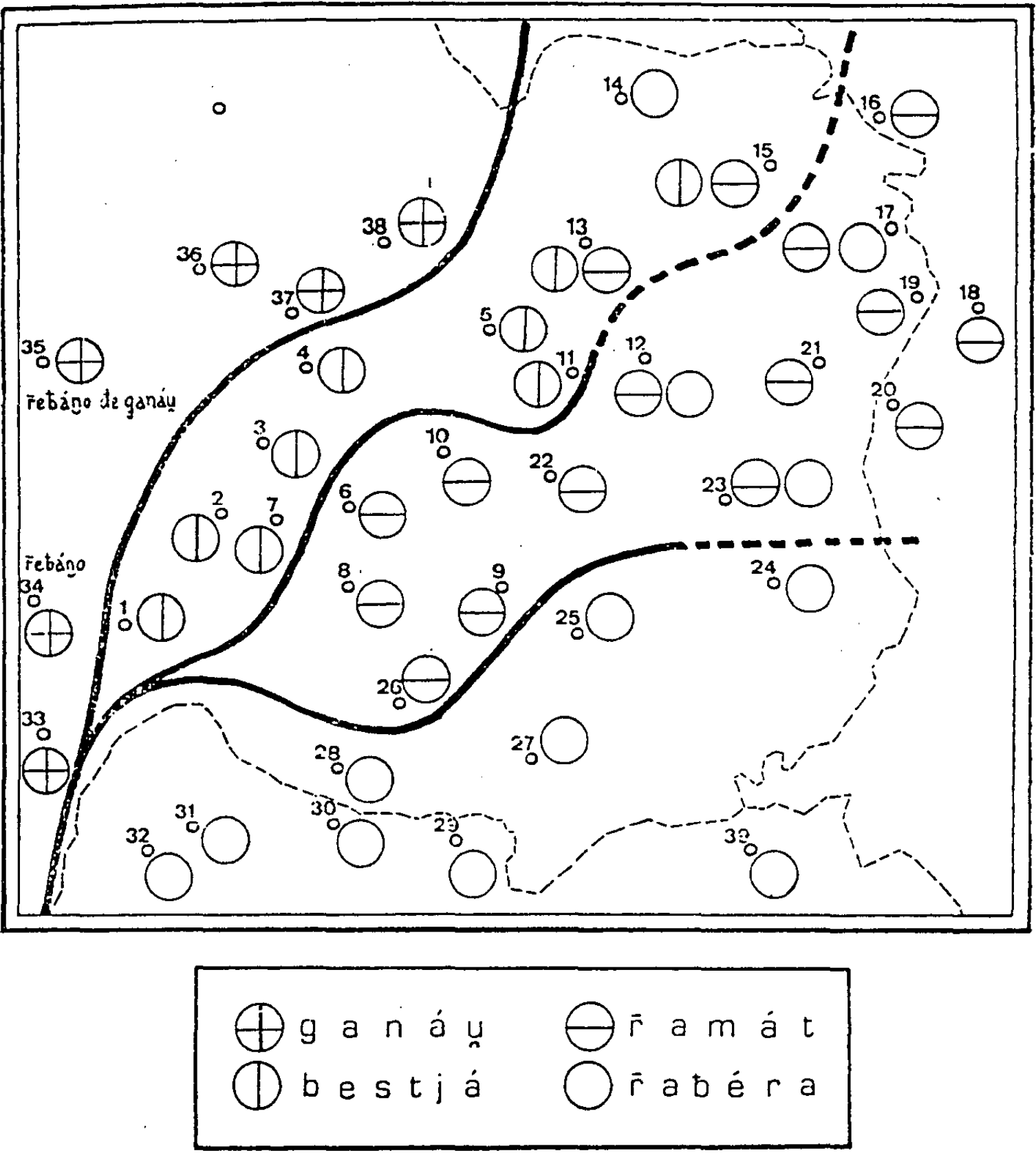

Mapa $1 .^{\circ}$ I6 


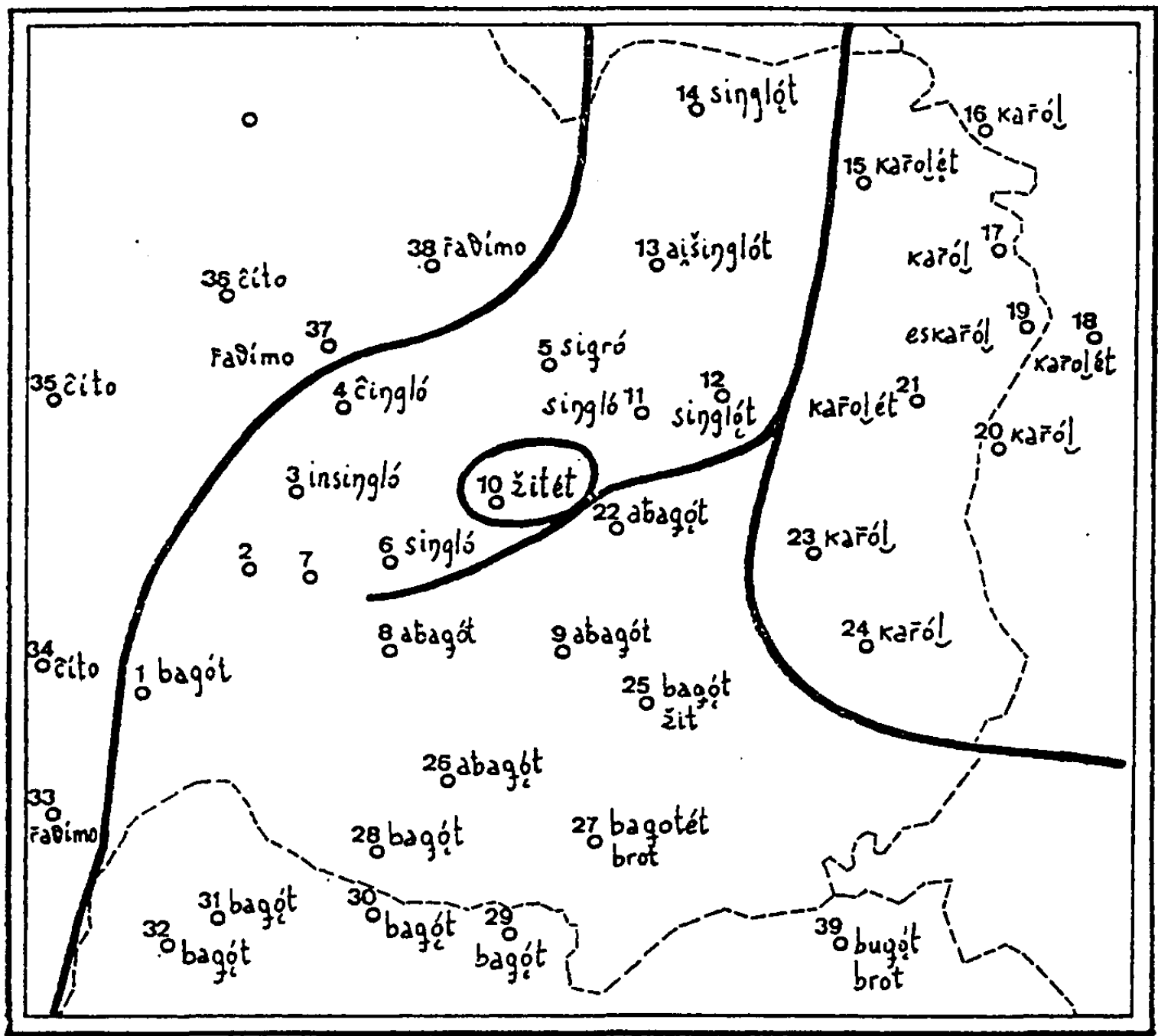

Mapa $0 .{ }^{\circ} 7$ 


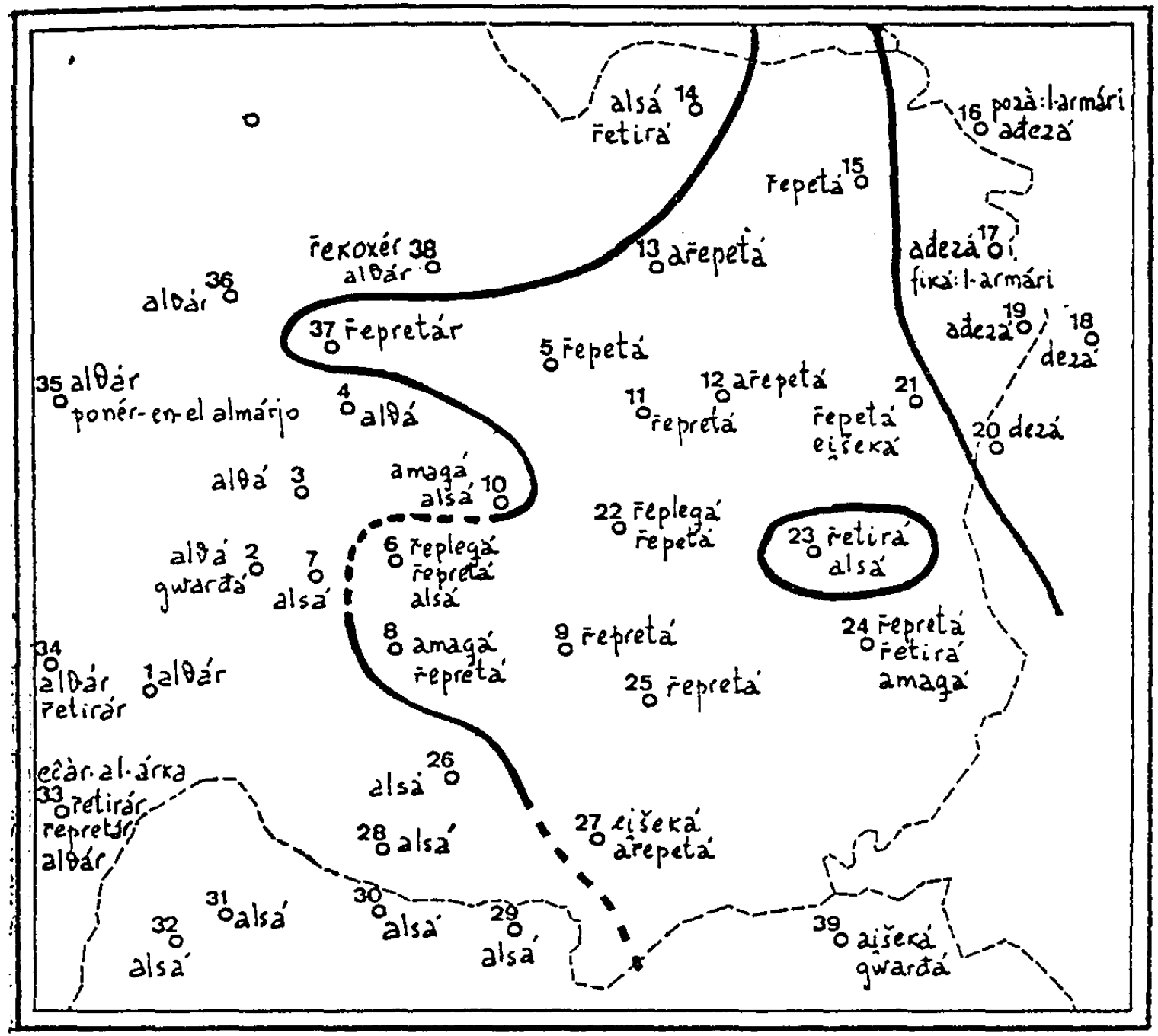

Mapa n. ${ }^{\circ} 8$ 


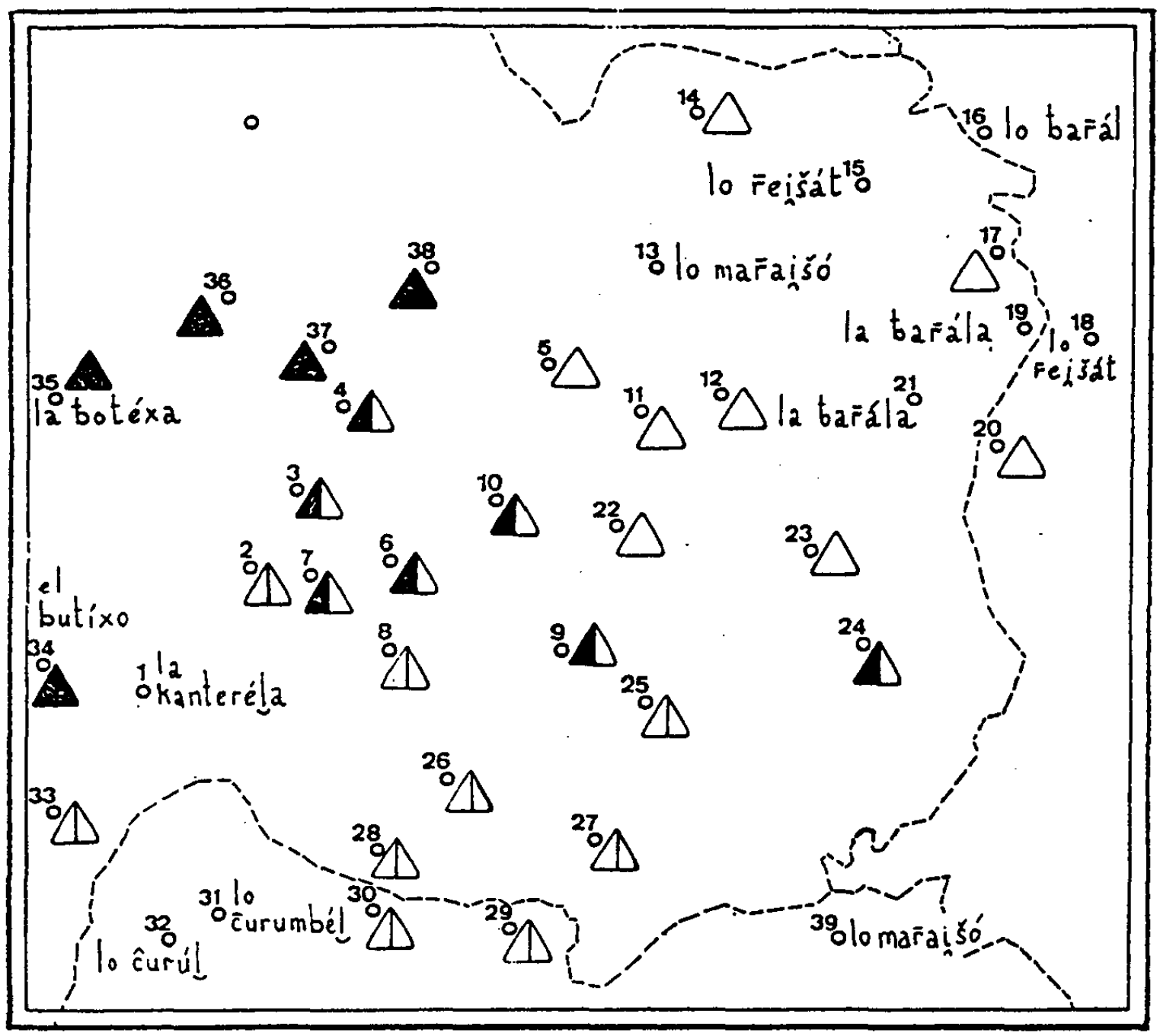
Ala kantaríka
$\triangle$ la picéla
$\triangle$ la kantréla
$\triangle$ el corílo,lon

Mapa n.* 19 


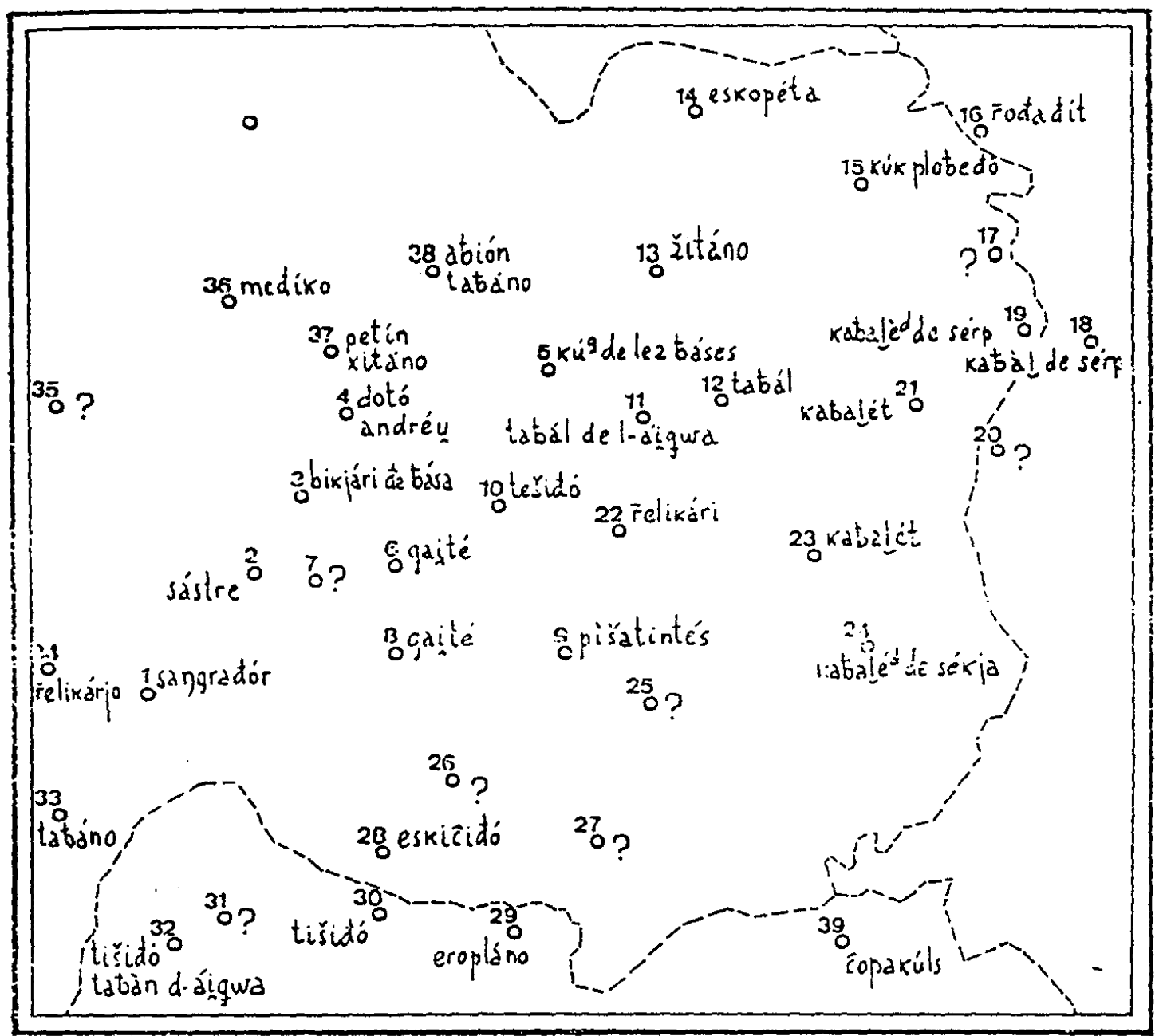

Mapa $110^{\circ} 20$ 